\title{
Perineurial Glia Are Essential for Motor Axon Regrowth following Nerve Injury
}

\author{
Gwendolyn M. Lewis and 1 Sarah Kucenas \\ Department of Biology, University of Virginia, Charlottesville, Virginia 22904
}

Development and maintenance of the peripheral nervous system (PNS) are essential for an organism to survive and reproduce, and damage to the PNS by disease or injury is often debilitating. Remarkably, the nerves of the PNS are capable of regenerating after trauma. However, full functional recovery after nerve injuries remains poor. Peripheral nerve regeneration has been studied extensively, with particular emphasis on elucidating the roles of Schwann cells and macrophages during degeneration and subsequent regeneration. In contrast, the roles of other essential nerve components, including perineurial glia, are poorly understood. Here, we use laser nerve transection and in vivo, time-lapse imaging in zebrafish to investigate the role and requirement of perineurial glia after nerve injury. We show that perineurial glia respond rapidly and dynamically to nerve transections by extending processes into injury sites and phagocytizing debris. Perineurial glia also bridge injury gaps before Schwann cells and axons, and we demonstrate that these bridges are essential for axon regrowth. Additionally, we show that perineurial glia and macrophages spatially coordinate early debris clearance and that perineurial glia require Schwann cells for their attraction to injury sites. This work highlights the complex nature of cell-cell interactions after injury and introduces perineurial glia as integral players in the regenerative process.

Key words: motor nerve; nerve injury; perineurial glia; regeneration; Schwann cells; zebrafish

\section{Introduction}

In all vertebrate peripheral nerves, axon-Schwann cell complexes are bundled into fascicles by the perineurium (see Fig. 1A). The mature perineurium is a cellular sheath formed by concentrically arranged layers of flattened, interdigitated perineurial cells that originate in the CNS as glia (Akert et al., 1976; Schmidt et al., 1997; Kucenas et al., 2008; Clark et al., 2014). These cells function to protect the nerve and regulate the transport of material between the interior and exterior of the fascicle (Burkel, 1967; Bourne, 1968; Kristensson and Olsson, 1971; Akert et al., 1976). Previously, we showed that perineurial glia play an essential role in nerve development (Binari et al., 2013; Kucenas et al., 2008; Clark et al., 2014). However, how they respond to nerve injury and participate in regeneration is poorly understood.

Immediately after a nerve transection, proximal and distal stump axons begin to fragment and degenerate back from the injury site in a process called acute axonal degeneration (AAD) (Kerschensteiner et al., 2005). Distal stump axons then begin

\footnotetext{
Received May 12, 2014; revised July 25, 2014; accepted Aug. 11, 2014.

Author contributions: G.M.L. and S.K. designed research; G.M.L. performed research; G.M.L. contributed unpublished reagents/analytic tools; G.M.L. and S.K. analyzed data; G.M.L. and S.K. wrote the paper.

This work was supported by the National Institutes of Health Grant NS072212 to S.K., Grant NS051140 to G.M.L., and the University of Virginia Fund for Excellence in Science and Technology to S.K. We thank members of the S.K. laboratory for valuable discussions; Lori Tocke for zebrafish care; Travis Lewis for help with diagrammatic representations; and Dr. Michael Granato for sharing the following fish lines: $\operatorname{Tg}(\mathrm{NBT}: d s r e d)^{2 f 148}$, colourless $\left(\mathrm{cls}{ }^{\mathrm{tw} 11}\right), \operatorname{Tg}(\operatorname{mnx} 1$ : WIds-GFP) ${ }^{160}$, and Tg(spi1:Gal4,UAS:EGFP) ${ }^{2 f 149}$.

The authors declare no competing financial interests.

Correspondence should be addressed to Dr. Sarah Kucenas, Department of Biology, Physical \& Life Sciences Building, Room 312, PO Box 400328, University of Virginia, Charlottesville, VA 22904-4328. E-mail: sk4ub@virginia.edu.

DOI:10.1523/JNEUROSCI.1906-14.2014

Copyright $\odot 2014$ the authors $\quad 0270-6474 / 14 / 3412762-16 \$ 15.00 / 0$
}

Wallerian degeneration, which is characterized by a latent period followed by distal axon fragmentation (Waller, 1850; George et al., 1995; Villegas et al., 2012). During these degenerative processes, Schwann cells rapidly transdifferentiate, phagocytize their own myelin, and recruit macrophages to clear debris (Perry et al., 1995; Arthur-Farraj et al., 2012). As regeneration begins, a tissue bridge forms to connect the proximal and distal stumps. Schwann cells then infiltrate this bridge, organize into cellular columns, and help guide newly regrowing axons across the gap and back to their original targets (Nguyen et al., 2002; McDonald and Zochodne, 2003; McDonald et al., 2006; Parrinello et al., 2010; for review, see Chen et al., 2007; Vargas and Barres, 2007; Wang et al., 2012). The role of the perineurium throughout these processes is poorly understood, although several studies have hypothesized that the initial tissue bridge could be perineurial in origin (Scaravilli, 1984; Schroder et al., 1993). In support of this hypothesis, electron microscopy studies show that axons regrow through tracts containing both Schwann cell and perineurial lamellae (Thomas and Jones, 1967; Morris et al., 1972). However, no study has ever focused on perineurial glial behavior after injury, and it is not known how these cells coordinate with other cell types or whether they are required for axon regrowth.

Here we use laser axotomy and in vivo, time-lapse confocal imaging to transect spinal motor nerves in live transgenic zebrafish and visualize perineurial glial responses after injury. We show that perineurial glia respond immediately to nerve transection by extending processes toward the injury site and phagocytizing debris. Perineurial processes bridge the proximal and distal stumps; and in the absence of these bridges, axon regrowth is impaired. Additionally, we show that debris clearance appears to be coordinated between perineurial glia, macrophages, and 
Table 1. Descriptions and abbreviations of transgenic lines used in this study ${ }^{a}$

\begin{tabular}{|c|c|c|}
\hline Transgene name & Abbreviation & Description of expression \\
\hline $\operatorname{Tg}(n k x 2.2 a: m e g f p)^{v u 1}$ & $n k x 2.2 a: g f p$ & $\begin{array}{l}\text { Membrane EGFP in } n k \times 2.2 a^{+} \text {cells (perineur- } \\
\text { ial glia, floorplate) }\end{array}$ \\
\hline $\operatorname{Tg}(o l i g 2: d s r e d 2)^{\text {vu19 }}$ & olig2:dsred & $\begin{array}{l}\text { Cytosolic DsRed in olig2 }{ }^{+} \text {cells (motor neu- } \\
\text { rons/axons) }\end{array}$ \\
\hline $\operatorname{Tg}($ mpeg1:EGFP) & mpeg1:gfp & $\begin{array}{l}\text { Cytosolic EGFP in mpeg } 1^{+} \text {cells (macro- } \\
\text { phages) }\end{array}$ \\
\hline $\operatorname{Tg}($ sox10:EOs) & sox10:eos & $\begin{array}{l}\text { Cytosolic photoconvertible Eos in sox } 10^{+} \text {cells } \\
\text { (Schwann cells) }\end{array}$ \\
\hline $\operatorname{Tg}(N B T: D s R e d)$ & nbt:dsred & Cytosolic DsRed in $n b t^{+}$cells (neurons/axons) \\
\hline Tg(spi1:Gal4,UAS:EGFP) ${ }^{2 f 149}$ & spi1:gfp & $\begin{array}{l}\text { Cytosolic EGFP in spi } 1^{+} \text {cells (leukocytes, micro- } \\
\text { glia) }\end{array}$ \\
\hline $\operatorname{Tg}(m n \times 1: M m u . W I d s-G F P)$ & $m n \times 1:$ wlds-gfp & $\begin{array}{l}\text { WId }{ }^{s} \text { and nuclear GFP in } m n x^{+} \text {cells (motor } \\
\text { neurons/axons) }\end{array}$ \\
\hline
\end{tabular}

${ }^{a}$ All lines used were stable, germline transgenics. Cell types listed for each transgene are only those pertinent to this study.

Schwann cells and that perineurial glial attraction to injury sites is dependent on Schwann cells. These data reveal an essential role for perineurial glia during regeneration and demonstrate the importance of Schwann cell-perineurial glial interactions after injury.

\section{Materials and Methods}

Fish husbandry. All animal studies were approved by the University of Virginia Institutional Animal Care and Use Committee. Zebrafish strains used in this study included $\operatorname{Tg}(n k \times 2.2 a: \text { megfp })^{v u 17}$ (Kirby et al., 2006; Kucenas et al., 2008), Tg(olig2: dsred2) ${ }^{v u 19}$ (Kucenas et al., 2008), Tg(mpeg1:EGFP) (Ellett et al., 2011), $\mathrm{Tg}$ (sox10:eos) (Prendergast et al., 2012), Tg(NBT:DsRed) (Peri and Nüsslein-Volhard, 2008), Tg(spil: Gal4,UAS:EGFP) ${ }^{z f 149}$ (Peri and Nüsslein-Volhard, 2008), Tg(mnxl: Mmu.Wlds-GFP) (Rosenberg et al., 2012), and colourless ${ }^{\text {tw11 }}\left(\right.$ sox10 $\left.^{-/-}\right)$ (Kelsh et al., 1996). Table 1 describes the expression and abbreviations of all of these lines. Embryos were produced by pairwise matings, raised at $28.5^{\circ} \mathrm{C}$ in egg water, staged according to hours or days post fertilization (hpf and dpf, respectively) and embryos of either sex were used for all experiments described below (Kimmel et al., 1995). Embryos used for immunohistochemistry and microscopy were treated with $0.003 \%$ phenylthiourea (PTU) in egg water to reduce pigmentation.

In vivo imaging. At $24 \mathrm{hpf}$, all embryos used for live imaging were manually dechorionated and transferred to egg water containing PTU to block pigment formation. At specified stages, embryos were anesthetized using 3-aminobenzoic acid ester (Tricaine), immersed in $0.8 \%$ lowmelting point agarose, and mounted on their sides in glass-bottomed 35 $\mathrm{mm}$ Petri dishes (Electron Microscopy Sciences). Images were captured using either $40 \times$ (NA 1.2) or $63 \times$ (NA 1.2) water-immersion objectives mounted on a motorized Zeiss AxioObserver Z1 microscope equipped with a Quorum WaveFX-X1 spinning disc confocal system (Quorum Technologies). For time-lapse imaging, $z$-image stacks were collected every $5 \mathrm{~min}$ for $3-4 \mathrm{~h}$, and $3 \mathrm{D}$ datasets were compiled using Sorenson 3 video compression (Sorenson Media) and exported to QuickTime (Apple) to create movies. Image adjustments were limited to contrast enhancement and level settings using MetaMorph software and ImageJ.

DAPT treatment. Stock solutions for DAPT (565784; $N-[(3,5-$ difluorophenyl)acetyl]-L-alanyl-2-phenyl]glycine-1,1-dimethylethyl ester; EMD Chemicals) were made in DMSO and used at $100 \mu \mathrm{M}$ as previously described (Binari et al., 2013). DAPT was diluted in PTU egg water plus DMSO to a final concentration of $1 \%$ DMSO and mixed by vortexing. Larvae were placed in $3 \mathrm{ml}$ of PTU egg water containing DAPT in $35 \mathrm{~mm}$ Petri dishes from 48 to $72 \mathrm{hpf}$. Larvae were then washed in PTU egg water and moved to fresh PTU until $6 \mathrm{dpf}$ for experiments. Control larvae were placed in $3 \mathrm{ml}$ of PTU egg water containing 1\% DMSO alone from 48 to $72 \mathrm{hpf}$, washed in PTU egg water, and then moved to fresh PTU until 6 dpf for experiments.

LysoTracker staining. To label organelles with low $\mathrm{pH}, 4 \mathrm{dpflarvae}$ were immersed in $20 \mu \mathrm{M}$ LysoTracker Red DND-99 (Invitrogen)/2\% DMSO or $10 \mu \mathrm{M}$ LysoTracker Deep Red (Invitrogen)/1\% DMSO in egg water for $2 \mathrm{~h}$ at $23^{\circ} \mathrm{C}$. Larvae were then rinsed once with egg water and immediately mounted for imaging.

Immunohistochemistry. Larvae were fixed in AB Fix (4\% PFA, $0.1 \%$ Triton X-100, $1 \times$ PBS) for $3 \mathrm{~h}$ at $23^{\circ} \mathrm{C}$, followed by a $5 \mathrm{~min}$ wash with PBSTx (1\% Triton X-100, $1 \times$ PBS), a 5 min wash with DWTx $(1 \%$ Triton $\mathrm{X}-100$ in distilled water), a 5 min wash with acetone at $23^{\circ} \mathrm{C}$, and a $10 \mathrm{~min}$ wash with acetone at $-20^{\circ} \mathrm{C}$. Larvae were preblocked in $5 \%$ goat serum/PBSTx for $1 \mathrm{~h}$, then incubated in primary antibody for $1 \mathrm{~h}$ at $23^{\circ} \mathrm{C}$ and overnight at $4^{\circ} \mathrm{C}$. The primary antibodies used included mouse antiacetylated tubulin (1:5000, Sigma), rabbit antibody to Sox10 (1:5000) (Binari et al., 2013), mouse antibody to ZO-1 (zona occludins 1; 1:200, Invitrogen), and rabbit antibody to MBP (1:250) (Kucenas et al., 2009). Larvae were washed extensively with $1 \times$ PBSTx and incubated in secondary antibody for $1 \mathrm{~h}$ at $23^{\circ} \mathrm{C}$ and overnight at $4^{\circ} \mathrm{C}$. Secondary antibodies used were AlexaFluor-488 goat anti-rabbit, AlexaFluor-568 goat anti-rabbit, or AlexaFluor-568 goat anti-mouse, AlexaFluor-647 goat anti-rabbit and AlexaFluor-647 goat anti-mouse (Invitrogen). Larvae were washed extensively with $1 \times$ PBSTx and stored in 50\% glycerol/PBS at $4^{\circ} \mathrm{C}$ until imaging. Larvae were mounted on their sides in $0.8 \%$ lowmelting point agarose on glass-bottomed $35 \mathrm{~mm}$ Petri dishes and imaged using the confocal microscope described above. Image adjustments were limited to contrast enhancement and level settings using MetaMorph software and ImageJ.

Data quantification and statistical analysis. All graphically presented data represent the mean of the analyzed data. Statistical analyses and graphing were performed with GraphPad Prism software. The level of significance was determined by using an unpaired $t$ test using a confidence interval of $95 \%$. For Figure $4 E$, we ran a $z$-test to compare two proportions using independent samples and compared the proportion of nerves exhibiting "no regrowth" between each group. We again used a confidence interval of $95 \%$ to determine significance.

Nerve transection. Nerve transections were performed using a MicroPoint Laser (Andor Technology) as previously published (Rosenberg et al., 2012; Banerjee et al., 2013; Binari et al., 2013; Lewis and Kucenas, 2013), attached to a spinning disk confocal system (Quorum Technologies) consisting of a nitrogen-pumped dye laser (wavelength $435 \mathrm{~nm}$ ) controlled by MetaMorph Version 7.7. Ablation laser settings ranged from power 15 to 20 depending on the age of the larvae and nerve position. One or two motor nerves per larva in hemisegments 10-16 were transected in all experiments. To transect nerves, a thin elliptical ROI was drawn digitally in MetaMorph over the image of the nerve, and the nerve was laser pulsed precisely within the ROI until the nerve appeared transected, whereby fluorescence did not refill the ROI in $>10 \mathrm{~s}$. Successful transections with this protocol were independently confirmed by identifying the presence of axonal degeneration in transgenic lines that label motor axons (data not shown). In vivo imaging of transected nerves was performed as described above. For multiday experiments, larvae were demounted immediately after injury, allowed to recover in PTU, and remounted for imaging at $24 \mathrm{and} / \mathrm{or} 48 \mathrm{~h}$ after injury.

Transmission electron microscopy. Larvae were prepared for electron microscopy using microwave fixation (Panasonic Model \#NNSD967S) and were kept on ice at $\sim 15^{\circ} \mathrm{C}$ throughout all microwave steps to prevent sample heating. The $6 \mathrm{dpf}$ larvae were killed with Tricaine and fixed in $2 \%$ glutaraldehyde $/ 4 \%$ PFA in $0.1 \mathrm{~m} \mathrm{~PB}$. Samples were pulsed in the microwave, then kept in fixative for $2 \mathrm{~h}$ at $23^{\circ} \mathrm{C}$. Samples were washed in $0.1 \mathrm{M}$ $\mathrm{PB}$ for $30 \mathrm{~min}$, transferred to $1 \% \mathrm{OsO} 4$ in $0.1 \mathrm{M} \mathrm{PB}$, pulsed in the microwave, then left for $1 \mathrm{~h}$ at $23^{\circ} \mathrm{C}$. Samples were washed in $0.1 \mathrm{M}$ PB for 30 $\mathrm{min}$, followed by $5 \mathrm{~min}$ rinses in $50 \%$ and $70 \% \mathrm{EtOH}$. Preparations were stained en bloc with $4 \%$ uranyl acetate in $70 \% \mathrm{EtOH}$ and pulsed in the microwave. Samples were then subjected to ethanol dehydration and pulsed in the microwave after each change in solution: $70 \%$ ethanol, $95 \%$ ethanol, and $100 \%$ ethanol twice. Preparations were transferred to $100 \%$ acetone, pulsed in the microwave, changed to new 100\% acetone, and pulsed in the microwave again. Samples were put in a 1:1 acetone/EMBED mix and left overnight at $23^{\circ} \mathrm{C}$, then changed to $100 \%$ EMBED and left uncapped for $6 \mathrm{~h}$ to allow evaporation of any remaining acetone. Finally, samples were placed into fresh EMBED and left to cure overnight in a $60^{\circ} \mathrm{C}$ oven. Ultrathin sections $(70 \mathrm{~nm})$ were obtained on a 
Leica UCT ultramicrotome, transferred to copper grids, and counterstained with uranyl acetate. Sections were visualized on a JEOL 1010 Transmission electron microscope and imaged with a 16 megapixel SIA12C camera (Scientific Instruments and Applications).

Morpholino injections. The spilb translation blocking morpholino oligonucleotide (MO) (5'-GATATACTGATACTCCATTGGTGGT-3') (Rhodes et al., 2005; Villegas et al., 2012) was purchased from Gene Tools. The MO was dissolved in water to create a stock solution of $2 \mathrm{~mm}$ and diluted in water and Phenol red to create a working injection concentration of $0.5 \mathrm{~mm}$. We injected 2-4 $\mathrm{nl}$ into the yolk just below the single cell of fertilized embryos. All MO-injected embryos were raised in PTU embryo medium at $28.5^{\circ} \mathrm{C}$.

\section{Results}

The zebrafish spinal motor nerve as a model for studying glial behaviors during regeneration

To investigate the role and requirement of perineurial glia during degeneration and subsequent regeneration, we used the spinal motor nerve of $6 \mathrm{dpf}$ zebrafish larvae as a model. Zebrafish have recently become a common model system in which to study nerve degeneration and regeneration (O'Brien et al., 2009; Martin et al., 2010; Rosenberg et al., 2012; Villegas et al., 2012; O'Donnell et al., 2013), and previous work has shown that, by 5-6 dpf, both motor axons and their associated glia are differentiating and forming mature spinal motor nerves (Rosenberg et al., 2012; Binari et al., 2013). This makes regeneration studies feasible in a relatively mature, yet tractable, system.

Before performing nerve transections, we sought to further characterize spinal motor nerve ultrastructure in $6 \mathrm{dpf}$ zebrafish larvae. Using electron microscopy, we observed that, by this stage, motor axons were sorted with large-caliber axons associated with myelinating Schwann cells and small-diameter axons encased within immature Schwann cells, and both were bundled into a fascicle by a single layer of perineurial cells (Fig. 1B). Using $n k x 2.2 a$ :gfp;olig2:dsred larvae, where $n k x 2.2 a$ regulatory sequences drive expression of membrane tethered EGFP in perineurial glia and olig2 regulatory sequences drive expression of cytosolic DsRed in motor neurons/axons, we assayed the extent of perineurial ensheathment along motor nerves. At $6 \mathrm{dpf}$, spinal motor root axons were fully ensheathed by $n k x 2.2 a^{+}$perineurial glia from the motor exit point to the horizontal myoseptum, and perineurial processes frequently extended along axons well beyond the horizontal myoseptum (Fig. $1 C, D$ ). In the mature perineurium, differentiated perineurial cells express tight junction proteins, including zona occludins 1 (ZO-1), which connect individual cells together and give this nerve component its bloodnerve-barrier function. To investigate the extent of perineurial glial maturity and differentiation at $6 \mathrm{dpf}$, we labeled larvae with an antibody specific to ZO-1. Consistent with previous findings (Binari et al., 2013), we observed ZO-1 labeling along $n k x 2.2 a^{+}$ perineurial sheaths with the highest concentration near the motor exit point (Fig. 1E). To confirm that Schwann cells were present along motor nerves and at a similar stage of differentiation, we labeled 6 dpf larvae with antibodies specific to Sox10, a transcription factor expressed by all Schwann cells, and MBP, to label mature, myelinating glia. At this stage, we observed Sox $10^{+}$cells along both rostral and caudal nerve roots, and MBP immunoreactivity was present along the caudal motor root and absent from the rostral motor root (Fig. $1 F, G$ ). This MBP profile persisted out to $\sim 20 \mathrm{dpf}$ (data not shown); therefore, we concluded that rostral motor root axons are associated with nonmyelinating Sox $10^{+}$ glia, whereas caudal motor root axons are ensheathed by myelinating glia. Together, these data show that Sox $10^{+}$glia and perineurial glia are differentiating and forming mature structures along spinal motor nerve roots at $6 \mathrm{dpf}$. Therefore, these nerves are an ideal model to study the role of perineurial glia during nerve degeneration and regeneration.

To investigate the role of perineurial glia during motor nerve degeneration and subsequent regeneration, we developed an injury-response assay in live, $6 \mathrm{dpf}$ larvae. For this assay, we used a nitrogen pumped dye laser (MicroPoint, Andor Technology) to transect the rostral spinal motor nerve root, resulting in a complete axotomy of this nerve bundle (Lewis and Kucenas, 2013) (Fig. $1 H, I$ ). This assay is highly reproducible and similar to other published nerve transection assays (Rosenberg et al., 2012). Given that this method of transection relies on the use of a UV laser, we sought to confirm that motor axons were fully cut and not simply photobleached after injury. To investigate this possibility, we fixed $6 \mathrm{dpf}$ larvae after transection and labeled them with an antibody specific to acetylated tubulin to label all spinal motor axons. In these larvae, we consistently observed clear breaks in tubulin expression along rostral motor nerves where we had previously transected the nerve, but differential interference contrast imaging did not show any obvious tissue damage surrounding the lesions (Fig. 1I; and data not shown). From these data, we are confident that our nerve injury assay produces full and reproducible transections with no obvious damage to neighboring tissue.

To determine whether our injury assay produced axonal degeneration dynamics similar to previously published studies (Martin et al., 2010; Rosenberg et al., 2012; Villegas et al., 2012), we sought to characterize these events more carefully. Following transection of the rostral motor nerve, we observed that proximal and distal stump axons appeared to die back, gradually causing a widening of the injury gap (Fig. $1 J$ ). The phenomenon of axon die back, or AAD, is well established in mammalian systems (Kerschensteiner et al., 2005; Wang et al., 2012; Zochodne, 2012) and has been reported in zebrafish as well (Villegas et al., 2012). In our assay, we observed that AAD began along both stumps immediately after injury, increasing the distance between stumps by an average of $16.6 \mu \mathrm{m}$ over the first 2 hours post transection (hpt) ( $\mathrm{SD}=6.0, n=10)$. Interestingly, during our temporal analysis, we noticed that proximal stump AAD occurred earlier and at a faster rate than distal stump AAD (Fig. $1 K$ ). Ultimately, within a few hours, AAD along the distal stump gave way to Wallerian degeneration of distal axons, with individual axons fragmenting all at once, usually between 151 and 180 min post transection (mpt) (data not shown), which is consistent with previous findings in zebrafish (Martin et al., 2010; Rosenberg et al., 2012; Villegas et al., 2012). From these studies, we conclude that our nerve injury assay is highly reproducible with axon degeneration dynamics similar to previously reported models of axon injury in zebrafish (Martin et al., 2010; Rosenberg et al., 2012; Villegas et al., 2012), and therefore, provides an ideal model to investigate the role of perineurial glia in nerve degeneration and regeneration.

\section{Perineurial glia respond to spinal motor nerve root injury}

Although many studies have investigated the mechanisms that govern peripheral axon degeneration and regeneration, the role of perineurial glia during these processes is still poorly understood. Studies on fixed tissue preparations have hypothesized that: (1) perineurial cells may be the first cellular component to traverse injury gaps and connect proximal and distal stumps after nerve transection (Scaravilli, 1984; Schroder et al., 1993), and (2) axons regrow through tracks that contain both Schwann cell and perineurial lamella (Thomas and Jones, 1967; Morris et al., 1972). However, despite these indications that perineurial glia may be 


\section{A}
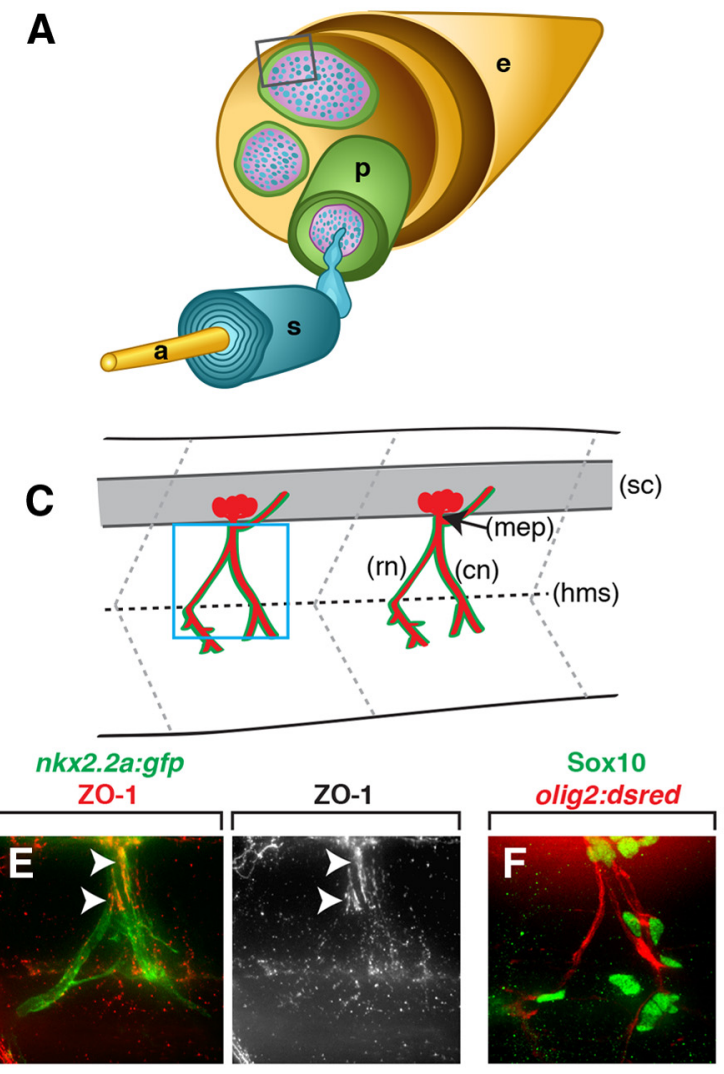

Sox 10
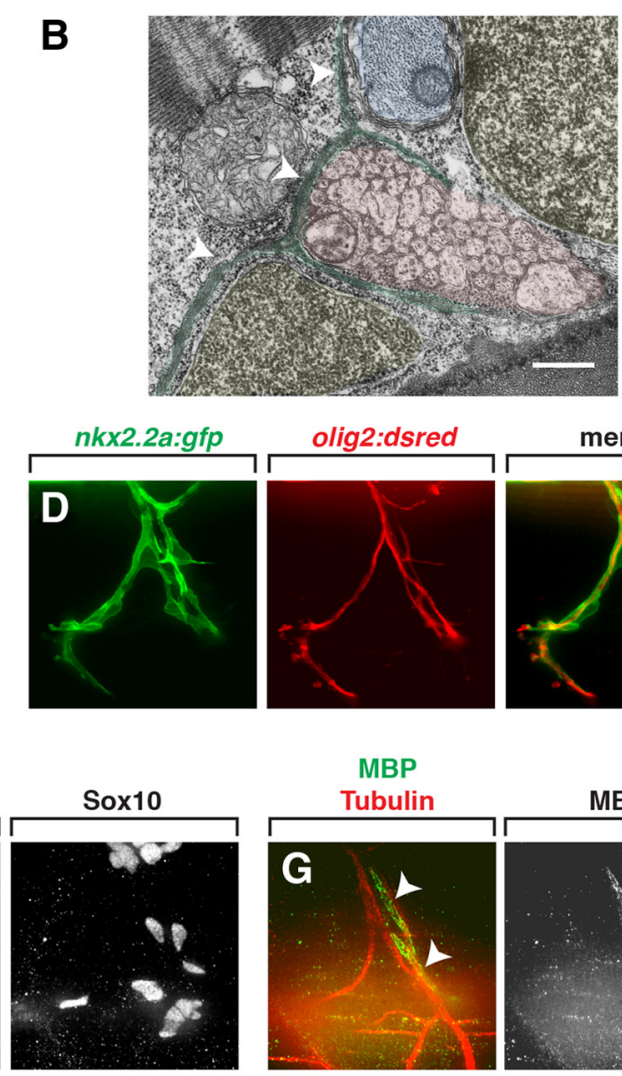

B
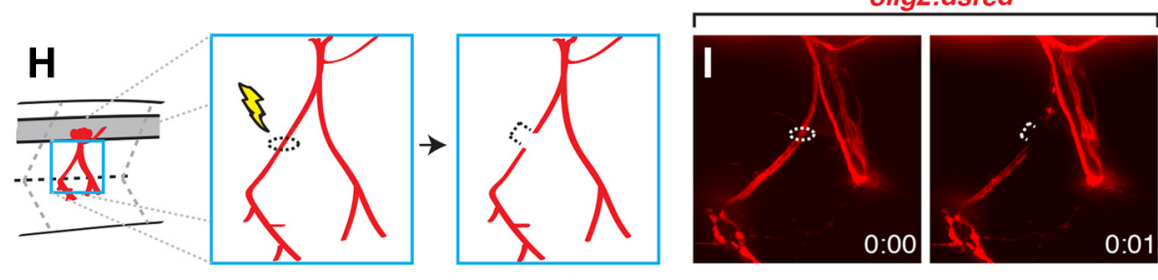

MBP

Tubulin
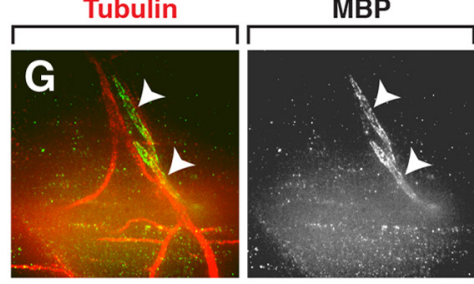

Tubulin

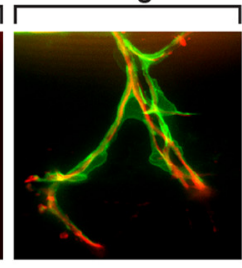

olig2:dsred
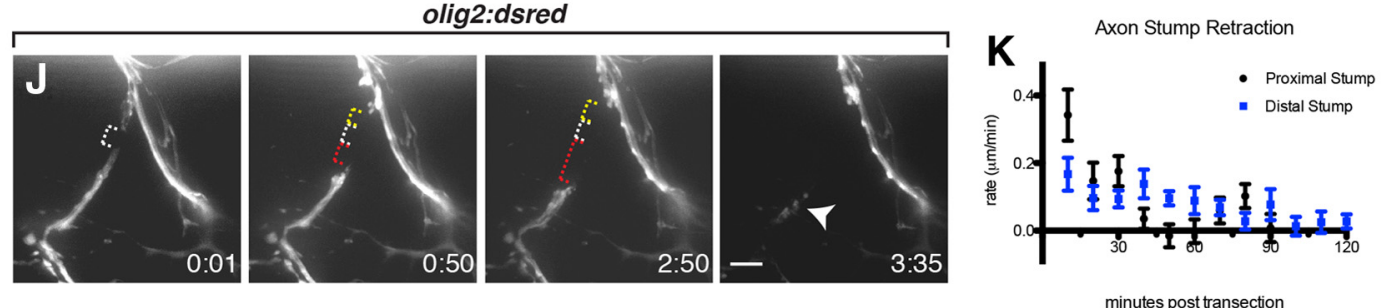

Figure 1. Spinal motor nerve root as a model for investigating the role of perineurial glia after injury. $A$, Diagrammatic representation of a cross section through an adult peripheral nerve shows axons (a) are wrapped by Schwann cells $(s)$ and bundled into a fascicle by the perineurium (p). Several fascicles are encased by the epineurium (e). Gray box represents approximate area represented in $\boldsymbol{B}$. $\boldsymbol{B}$, Transmission electron micrograph of a transverse section through the spinal motor nerve root of a wild-type $6 \mathrm{dpf}$ larva. Yellow shading represents $S c h w a n n$ cell nuclei. Pink represents a bundle of unmyelinated axons. Blue represents a myelinated axon. Arrowheads point to a single layer of perineurium, which is shaded green. $C$, Diagrammatic representation of a $6 \mathrm{dpf}$ larvae with dorsal to the top and anterior to the left. Blue box represents the imaging field used throughout experiments. sc, Spinal cord; $h m s$, horizontal myoseptum; mep, motor exit point; $\mathrm{rn}$, rostral nerve; $\mathrm{cn}$, caudal nerve. $\boldsymbol{D}, \operatorname{In}$ a $6 \mathrm{dpf} n k \times 2.2 a$ :gfp;olig2:dsred larva, $n k x 2.2 a^{+}$perineurial glia fully ensheath olig $2^{+}$motor axons. E, Z0-1 staining in a $n k x 2.2 a$ :gfp larva shows concentrated expression near the motor exit point (arrowheads) at $6 \mathrm{dpf}$. $\boldsymbol{F}$, Sox10 labeling is present along olig $2^{+}$motor axons at $6 \mathrm{dpf}$. G, MBP staining is present along the caudal but not rostral motor nerve bundle. $\boldsymbol{H}$, Diagrammatic representation of the rostral spinal motor nerve root transection assay we use in these studies. $I$, Rostral motor nerve transection in a $6 \mathrm{dpf}$ olig2:dsred larva. Dotted ellipse indicates ablated ROI; dotted bracket indicates injury gap. Tubulin staining is not present in the injury gap of the transected nerve.J, After transection at $6 \mathrm{dpf}$ in a oligz:dsred larva, olig2 $2^{+}$axons degenerate after transection. White dotted line indicates initial injury gap; yellow dotted line indicates proximal stump AAD; red dotted line indicates distal stump AAD; arrowhead points to debris after distal stump Wallerian degeneration. $\boldsymbol{K}$, Graphical representation of rate of proximal and distal stump AAD over time. Time in bottom right corners indicates minutes post transection (mpt). Scale bars: $A, 0.5 \mu \mathrm{m} ; C-J, 10 \mu \mathrm{m}$.

important for regeneration, perineurial glial behavior after injury has never been formally investigated.

To this end, we transected the rostral spinal motor nerve root in $6 \mathrm{dpf} n k x 2.2 a$ :gfp;olig2:dsred larvae $(n=11)$ using the assay we describe above coupled with in vivo, time-lapse imaging. These transections severed both motor axons and their ensheathing perineurial glial membranes and resulted in an average injury gap of $4.9 \mu \mathrm{m}(\mathrm{SD}=1.9, n=11)$ between the proximal and distal stumps at $1 \mathrm{mpt}$. We began time-lapse imaging immediately after the injury; and by $15 \mathrm{mpt}$, we observed that perineurial glia extended highly motile membrane processes toward the injury site from both the proximal and distal stumps (Fig. 2A; Movie 1). 
nkx2.2a:gfp;olig2:dsred

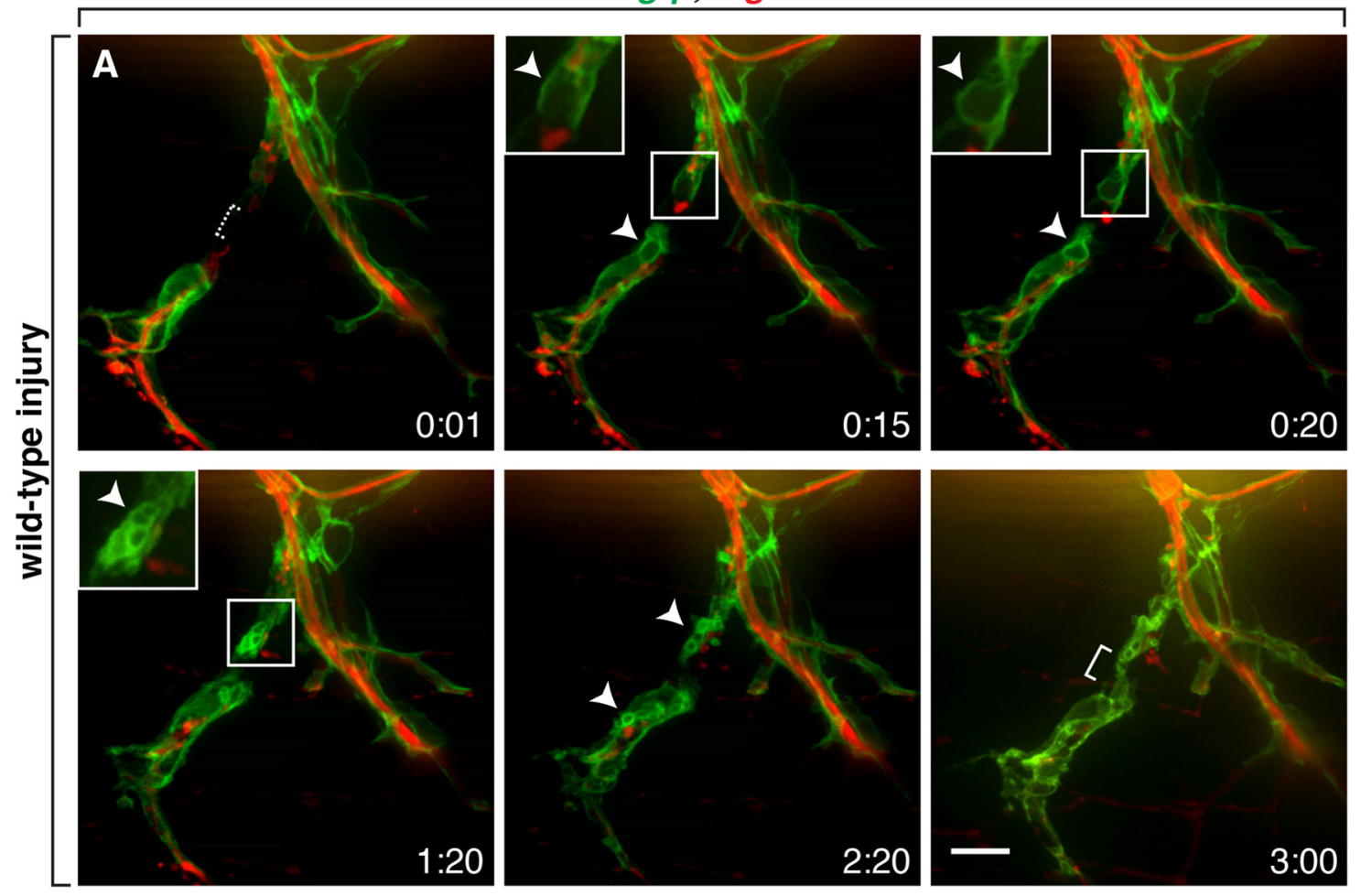

B Perinuerial Glial Injury Responses
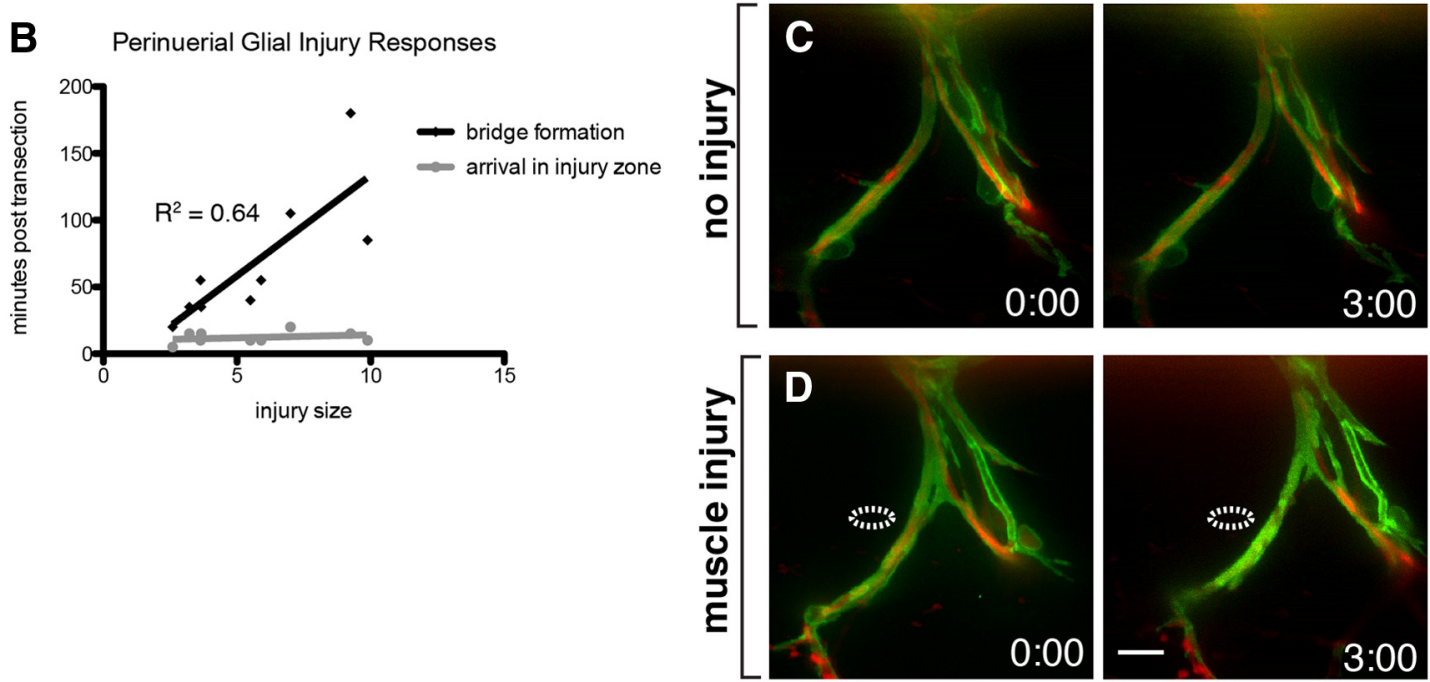

Figure 2. Perineurial glia respond to rostral motor nerve injury. Frames captured from a $3 \mathrm{~h}$ time-lapse movie of a $6 \mathrm{dpf} n \mathrm{nk}$ 2.2a:gfp;olig2:dsred larva beginning at $1 \mathrm{mpt}$ with dorsal to the top and anterior to the left. $\mathrm{mpt}$ is indicated in bottom right corner of each image. $A$, Perineurial glia respond to rostral spinal motor nerve root transection by extending processes into the injury site, forming vesicles (insets and arrowheads), and bridging the injury gap (bracket). $\boldsymbol{B}$, Graphical representation of the time it took perineurial glia to bridge the injury gap plotted against the initial injury size. $\boldsymbol{C}, \boldsymbol{D}$, Perineurial glial membranes are stable in both $(\boldsymbol{C})$ the absence of injury and $(\boldsymbol{D})$ after injury to tissue adjacent to the nerve. Dotted ellipse indicates ablated ROl. Scale bars, $10 \mu \mathrm{m}$.

Around this same time, vesicles formed in perineurial glial membranes near the transection site (Fig. 2A; Movie 1). Interestingly, these vesicle-like structures appeared along both stumps during the period of AAD and were particularly numerous along the proximal stump, which degenerates more rapidly (Fig. $2 A$; Movie 1). During the imaging window ( $3 \mathrm{~h}$ ) after nerve injury, perineurial glia eventually bridged the injury site, connecting the proximal and distal stumps, and remained along the distal stump after distal axons degenerated and were cleared (Fig. 2A; Movie 1).

To determine whether the size of the initial injury gap was correlated to the time it took perineurial glia to form bridges, we measured the size of the injury gap at $1 \mathrm{mpt}$ and plotted it against the time it took perineurial cells to extend processes into the injury site and bridge the gap. We found that, regardless of the size of the injury, perineurial glia always extended highly motile membrane processes toward the injury gap within $20 \mathrm{mpt}$ (Fig. $2 B$ ). However, as injury size increased, the time to bridge formation increased linearly, indicating that larger injuries take perineurial glia, respectively, longer to bridge (Fig. $2 B$ ). Interestingly, perineurial glia did not routinely bridge large injuries $(>10$ $\mu \mathrm{m})$ during the imaging window, which led us to hypothesize that the bridging behavior may be mediated by perineurialperineurial interactions. 


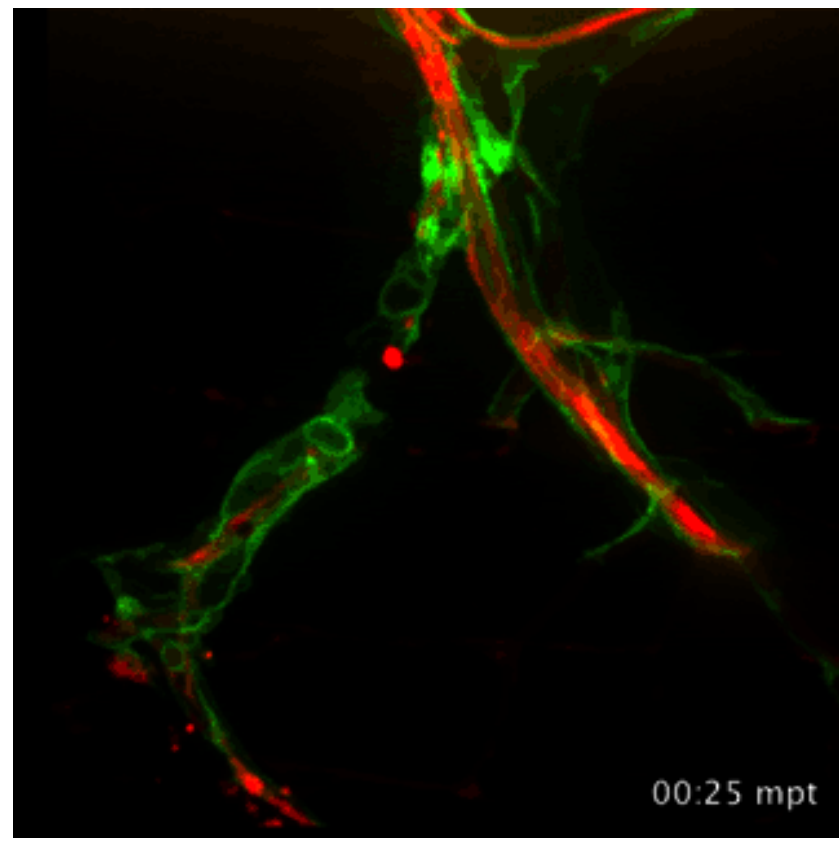

Movie 1. Perineurial glia respond to motor nerve transection. Four hour time-lapse movie of a $6 \mathrm{dpf} n k \times 2$.2a:gfp;olig2:dsred larva beginning at $1 \mathrm{mpt}$ with dorsal to the top and anterior to the left. Images were captured in 5 min intervals, and mpt is indicated in bottom right corner of each frame. White circle represents the approximate ablated ROI. Perineurial glia extend processes toward the injury site, form vesicles within their membranes, and bridge the injury gap.

To verify that the perineurial glial behaviors we observed were a response to nerve injury and not general damage or heat created by the laser, we created focal lesions in the muscle tissue $<10 \mu \mathrm{m}$ from rostral motor axons $(n=3)$ and assayed the perineurial glial response with time-lapse imaging. In the $3 \mathrm{~h}$ after injury, this type of damage did not elicit any changes in nearby perineurial glia compared with uninjured control larvae (Fig. 2C,D). Together, these data are consistent with the hypothesis that cues derived specifically from nerve damage induce a rapid change in perineurial glial behavior that results in perineurial glia extending processes toward the injury site, developing vesicles, and ultimately bridging the injury gap.

\section{Perineurial glia phagocytize debris after nerve injury}

While characterizing the response of perineurial glia to spinal motor nerve root injury, we noticed that the formation and temporal dynamics of perineurial glial vesicles coincided with periods of axonal degeneration (Figs. 1 and 2; Movie 1). Many vesicles formed along the proximal stump as it was rapidly degenerating during the first $45 \mathrm{mpt}$, and vesicles frequently formed along the distal stump during acute and Wallerian degeneration (Fig. 2A; Movie 1). However, we never observed perineurial vesicles along uninjured nerves or during normal nerve development before $6 \mathrm{dpf}$ (Fig. 2C; and data not shown). This led us to hypothesize that perineurial glia may be phagocytic and aid in debris clearance after injury. To investigate this hypothesis, we transected nerves in $6 \mathrm{dpf} n k \times 2.2 a$ :gfp;olig2:dsred larvae and looked for the presence of axonal fluorescence within perineurial glial vesicles. Single $z$-planes taken from time-lapse images showed that DsRed ${ }^{+}$axonal fluorescence was frequently present inside $\mathrm{GFP}^{+}$perineurial membrane vesicles during both AAD and Wallerian degeneration (Fig. $3 A-C$ ). Additionally, orthogonal views demonstrated that the $\mathrm{GFP}^{+}$perineurial vesicles were indeed spherical in nature and, therefore, morphologically con- sistent with phagocytic vesicles (Fig. 3D). Notably, not all vesicles contained axonal fluorescence, and it is possible that these vesicles contained debris derived from other nerve components, including myelin, Schwann cells, or extracellular matrix.

As an independent method of testing the phagocytic ability of perineurial glia, we used LysoTracker dye. LysoTracker is a membrane-permeable dye that fluoresces at acidic $\mathrm{pH}$, and this dye has previously been used in zebrafish to label phagosomes as they fuse with lysosomes and acidify (Peri and Nüsslein-Volhard, 2008). To confirm that the vesicle-like structures we observed after injury represent phagosomes or phagolysosomes, we treated 4 dpf $n k x 2.2 a$ :gfp larvae with $20 \mu \mathrm{M}$ LysoTracker Red, transected nerves and followed individual perineurial glial vesicles with timelapse imaging. After injury, we observed that perineurial vesicles became LysoTracker-positive over time (Fig. $3 E$ ), suggesting that these vesicles were acidifying. LysoTracker staining was present before injury and in uninjured controls; however, this staining never occurred within clearly defined perineurial vesicles and was likely the result of staining of lysosomes (data not shown) (Chazotte, 2011). These data demonstrate that after nerve damage, perineurial glia form phagocytic vesicles, many of which contain axonal debris. In our previous time-lapse imaging (Fig. $2 A$ ), we noticed that perineurial vesicles were most numerous along the proximal stump as those axons underwent AAD. Therefore, we conclude that perineurial glia initially focus their phagocytic activity along the proximal stump. This sets forth an intriguing hypothesis, where debris clearance may be spatially coordinated between different cell types after nerve injury.

\section{Perineurial glial bridges are required for axon regrowth}

Above, we show that perineurial glia bridge the injury gap between proximal and distal nerve stumps after transection, with timing that is dependent on the size of the injury (Fig. 2). Importantly, these bridges formed before new axons began to regenerate and remained intact after distal axons degenerated. Previous studies of sciatic nerve regeneration in rats showed that a tissue bridge forms to connect the proximal and distal stumps shortly after transection and that this bridge precedes the ingrowth of axons and Schwann cells (Schroder et al., 1993; McDonald and Zochodne, 2003; McDonald et al., 2006; Parrinello et al., 2010). Collectively, these data are consistent with the hypothesis that perineurial glia provide an essential tissue bridge that helps guide regenerating axons across the injury gap and back to their original targets.

To investigate this hypothesis, we assessed the ability of axons to regrow in the absence of perineurial glial bridges. Using $6 \mathrm{dpf}$ $n k x 2.2 a$ :gfp;olig2:dsred larvae, we deliberately created rostral spinal motor nerve transections that resulted in gaps of varying sizes, ranging from 3.5 to $20 \mu \mathrm{m}$. We then let the larvae recover and imaged them at $48 \mathrm{~h} \mathrm{hpt}$ to assess the presence or absence of perineurial bridges and the extent of axon regrowth. Previous studies in zebrafish demonstrate that motor axons begin to regrow after injury by $24 \mathrm{hpt}$, with full functional recovery achieved by $48 \mathrm{hpt}$ (Rosenberg et al., 2012), rendering $48 \mathrm{hpt}$ a suitable time point to assay axon regrowth.

In our studies, we defined full regrowth as the presence of an axon bundle at $48 \mathrm{hpt}$ that was approximately the same thickness and followed a similar path as the original, uninjured nerve (Fig. $4 A$ ). Moderate regrowth was defined as the presence of an axon bundle that was significantly thinner than the original nerve but followed a similar path (Fig. 4B). Finally, no regrowth was characterized as exhibiting either no axon regrowth from the proximal stump or sprouting that did not extend beyond the 
horizontal myoseptum (Fig. 4C). When we created transections that resulted in injury gaps that were $<7 \mu \mathrm{m}(n=9)$ and imaged at $48 \mathrm{hpt}$, perineurial glia always bridged injury sites and axons successfully regrew along these bridges following the original path (Fig. $4 A, B$ ). Of these nerves, $33 \%$ exhibited full regrowth and $66 \%$ exhibited moderate regrowth (Fig. 4E), which is consistent with clinical data describing that peripheral regeneration results in variable and often imperfect outcomes (Witzel et al., 2005; Zochodne, 2012). In contrast, when injury gaps ranged between 7 and $10 \mu \mathrm{m}(n=6)$, only $17 \%$ of nerves exhibited full axon regrowth at $48 \mathrm{hpt}, 50 \%$ exhibited moderate regrowth, and $33 \%$ exhibited no regrowth (Fig. $4 E$ ). In the cases of full and moderate regrowth, perineurial glia bridged the injury site in all but one instance. In this situation, axons appeared to reroute around the injury site and make their way back to a perineurial glial cell along the distal stump. Once meeting with the distal perineurial glia, axons then followed the glia along what appeared to be their original path (data not shown). In all cases of no regrowth, perineurial bridges were never present; and although we often observed axon sprouts from the proximal stump, they did not follow along any defined path and perineurial ensheathment of these sprouts was variable (Fig. 4C). Finally, when we created transections that resulted in injury gaps that were $>10 \mu \mathrm{m}$ $(n=6)$, we never observed full regrowth, $33 \%$ of cases had moderate regrowth with perineurial bridges, and $67 \%$ had no regrowth and no perineurial bridges (Fig. $4 C, E)$. Importantly, regardless of injury size, in 20 of 21 cases, the presence of a perineurial bridge was associated with axon regrowth, and the absence of a bridge was associated with no regrowth. We interpret this to mean that, as the size of the injury increased, the ability of perineurial glia to bridge became impaired; and when bridges did not form, axons were unable to regrow. Together, these data are consistent with the hypothesis that perineurial glial bridge formation is required for axon regrowth after injury.

To more directly test the requirement of perineurial glia for axonal regeneration, we assessed the ability of axons to regrow in the absence of perineurial glia.

In a previous study, we show that Notch signaling is required during a distinct temporal window (48-72 hpf) for perineurial glial development (Binari et al., 2013). During this window, treating embryos with either DAPT, a gamma secretase inhibitor, or genetically blocking Notch signaling via a dominant-negative form of the Notch intraceullar domain (NICD) cofactor, suppressor of
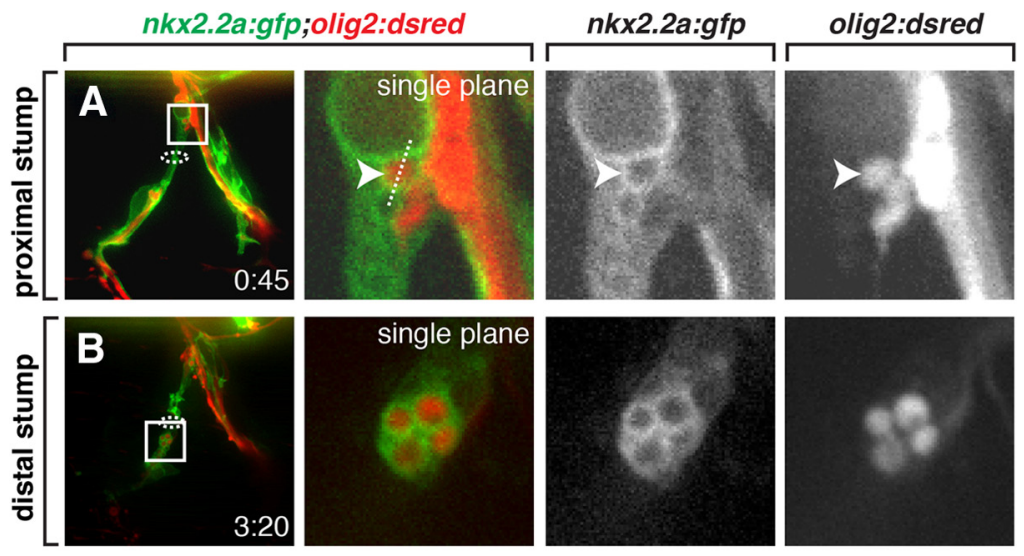

$n k x 2.2 a: g f p$
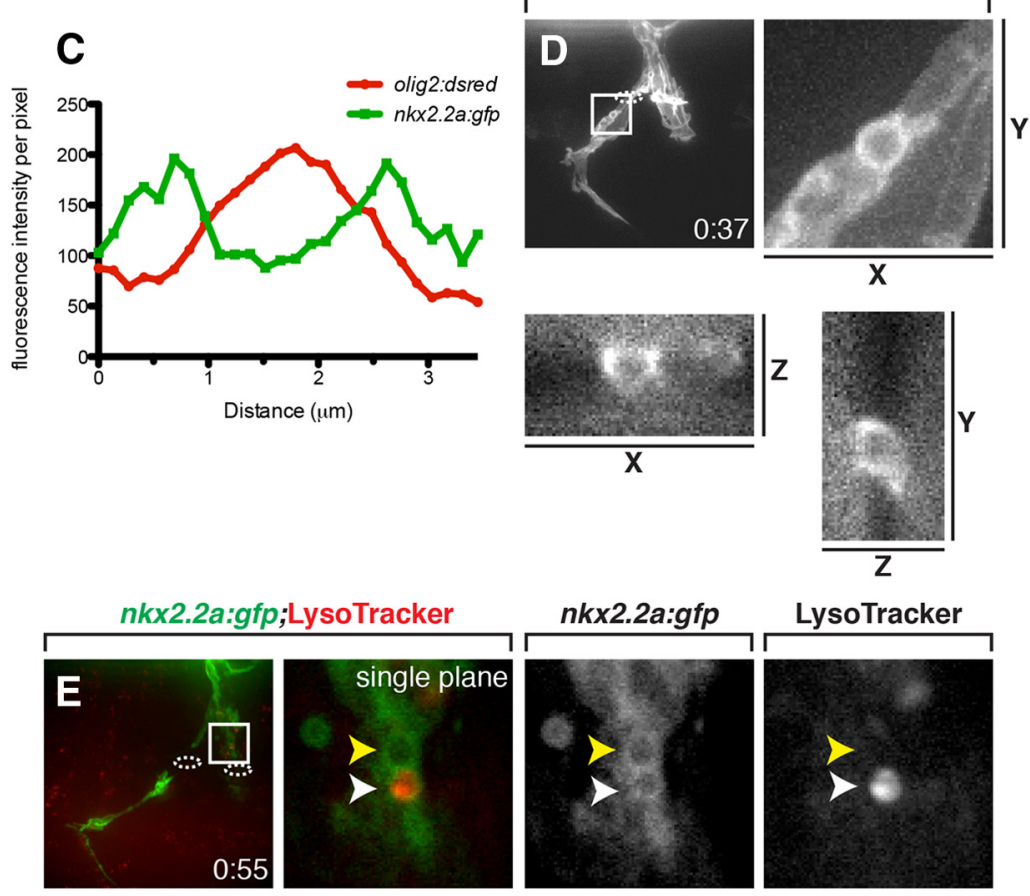

LysoTracker
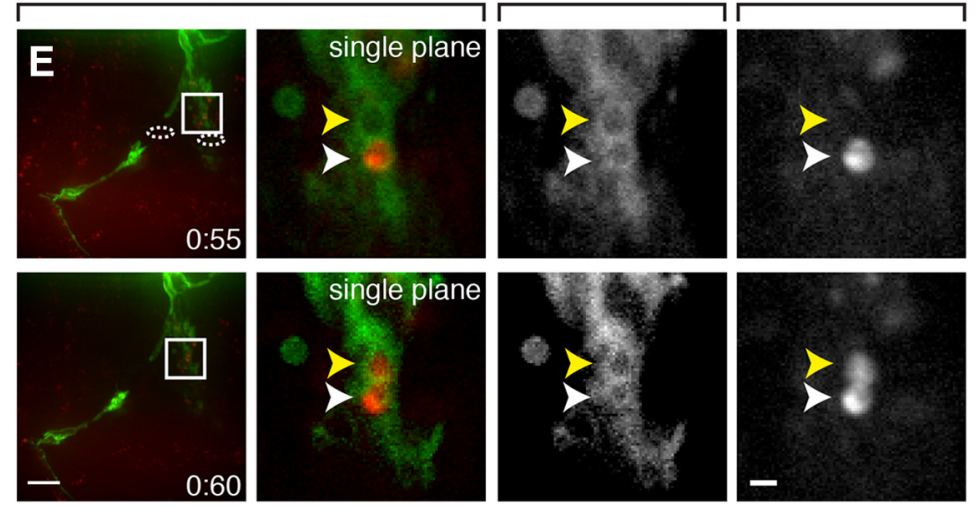

Figure 3. Perineurial glia phagocytize debris after nerve injury. Frames captured from a time-lapse movie of a $6 \mathrm{dpf} n k x 2.2 a$ : gfp;olig2:dsred larva beginning at $1 \mathrm{mpt}$ with dorsal to the top and anterior to the left. mpt is indicated in bottom right corner of each image; dotted ellipses indicate ablated ROls. Magnified regions (white boxes) are single $z$-planes where indicated. $\boldsymbol{A}, \boldsymbol{B}$, Rostral nerve transections in $6 \mathrm{dpf} n k \times 2.2 a$ :gfp;olig2:dsred larvae show olig2 ${ }^{+}$axon fragments (arrowheads) within $n k \times 2.2 a^{+}$ perineurial membranes along the proximal stump during $\operatorname{AAD}(\boldsymbol{A})$ and distal stump during Wallerian degeneration $(\boldsymbol{B})$. C, Fluorescence intensity of $n k x 2.2 a: g f p$ and oligz:dsred along the white dashed line ROI drawn in $\boldsymbol{A}$ shows an increase in oligz:dsred fluorescence within the $n k x 2.2 a$ :gfp fluorescing vesicle. $\boldsymbol{D}$, A perineurial vesicle shown with accompanying orthogonal views. $\boldsymbol{E}$, Rostral and caudal nerve transections of a $4 \mathrm{dpf} n k \times 2.2 a$ :gfp larva stained with LysoTracker. At $55 \mathrm{mpt}$, Lysotracker staining is visible within an $n k \times 2.2 a^{+}$perineurial vesicle (white arrowhead); and by $60 \mathrm{mpt}$, staining is visible within a second, adjacent vesicle (yellow arrowhead). Scale bars: full images, $10 \mu \mathrm{m}$; magnified insets, $1.5 \mu \mathrm{m}$.

hairless $(\mathrm{Su}(\mathrm{H}))$, led to a complete failure of perineurial glial migration into the PNS (Binari et al., 2013). Importantly, even though perineurial glia failed to exit the spinal cord, Schwann cells were still present along motor nerves after Notch perturbation, although they failed to myelinate axons (Binari et al., 2013). Therefore, this experimental paradigm allowed us to remove 

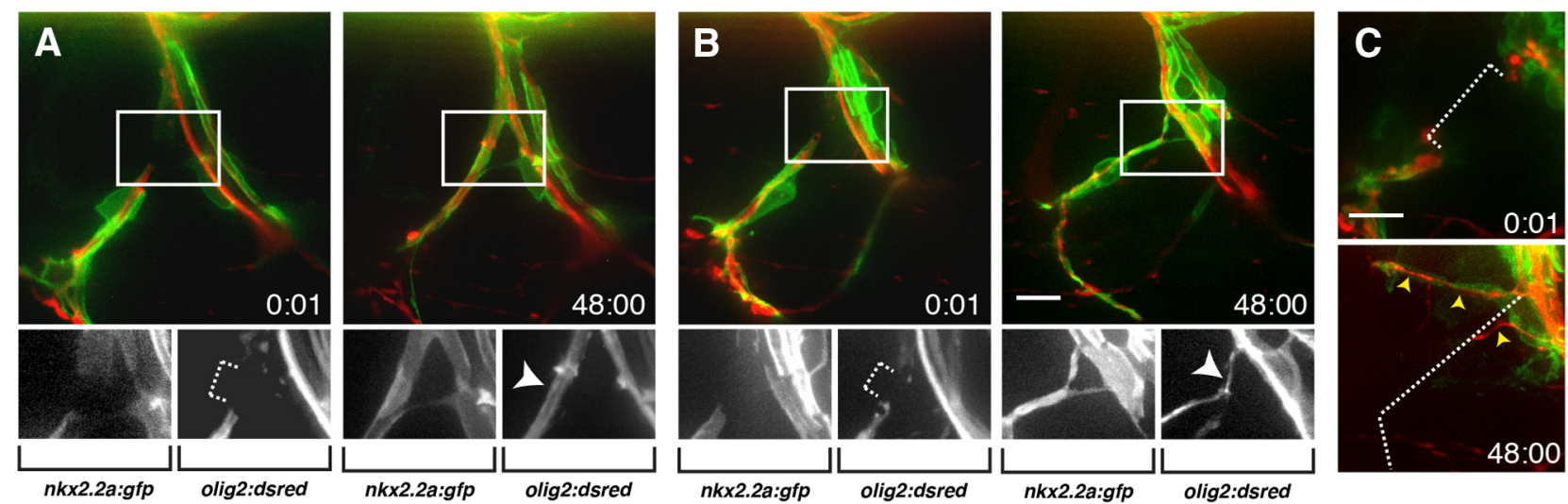

D
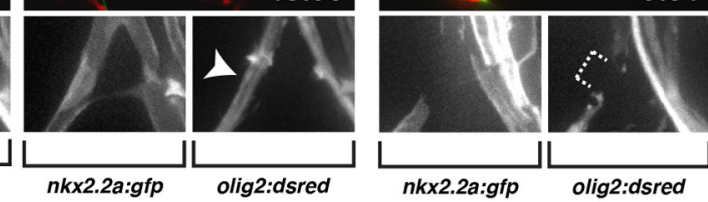

E
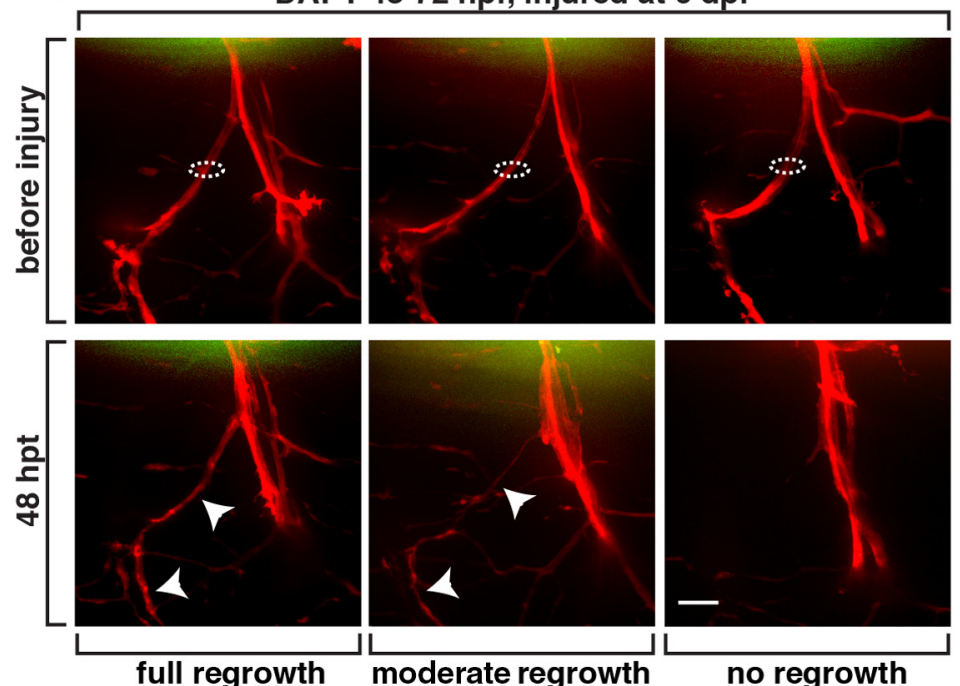

Regrowth Phenotypes at $48 \mathrm{hpt}$

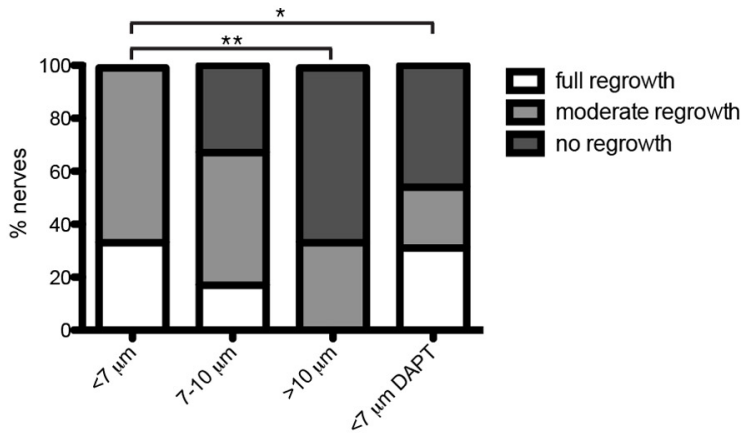

injury gap size

Figure 4. Perineurial bridges are essential for axon regrowth. All frames are live images taken from transected, $6 \mathrm{dpf} n \mathrm{nk2.2a:gfp;0lig2:dsred} \mathrm{larvae} \mathrm{with} \mathrm{dorsal} \mathrm{to} \mathrm{the} \mathrm{top} \mathrm{and} \mathrm{anterior} \mathrm{to} \mathrm{the} \mathrm{left.}$ $\mathrm{mpt}$ is indicated in bottom right corner of each image; dotted ellipses indicate ablated ROls. White boxes represent magnified images below; dashed brackets label the injury. $A$, A representative example of a transection that resulted in a $<7 \mu \mathrm{m}$ injury gap at $1 \mathrm{mpt}$ where axons exhibited full regrowth with a tight perineurial sheath by $48 \mathrm{hpt}$. $\boldsymbol{B}$, A representative example of a transection that resulted in a $<7 \mu \mathrm{m}$ injury gap at $1 \mathrm{mpt}$ and had moderate axon regrowth by $48 \mathrm{hpt}$. C, When a $>10 \mu \mathrm{m}$ injury gap at $1 \mathrm{mpt}$ was created, we observed no axon regrowth and aberrant axon sprouting (yellow arrowheads) at $48 \mathrm{hpt}$. D, DAPT treatment from 48 to $72 \mathrm{hpf} \mathrm{resulted} \mathrm{in} \mathrm{the} \mathrm{absence} \mathrm{of} \mathrm{perineurial} \mathrm{glia} \mathrm{along} \mathrm{motor} \mathrm{nerves} \mathrm{at} 6 \mathrm{dpf}$. Rostral nerve transections in these larvae resulted in a mix of full, moderate, and no regrowth phenotypes at $48 \mathrm{hpt}$. $\boldsymbol{E}$, Graphical representation of data in $\boldsymbol{A}-\boldsymbol{D}$. The number of nerves analyzed for each condition is as follows: $<7 \mu \mathrm{m}, n=9 ; 7-10$ $\mu \mathrm{m}, n=6 ;>10 \mu \mathrm{m}, n=6 ;<7 \mu \mathrm{m} \mathrm{DAPT}, n=13$. Significance presented represents the difference in the proportion of nerves with a "no regrowth" outcome. The difference in "no regrowth" between the $<7 \mu \mathrm{m}$ and $>10 \mu \mathrm{m}$ conditions was significant with $p=0.00424$. The difference in "no regrowth" between the $<7 \mu \mathrm{m}$ and $<7 \mu \mathrm{m}$ DAPT conditions was significant with $p=$ 0.01684. Scale bars, $10 \mu \mathrm{m}$.

perineurial glia from motor nerves but leave Schwann cells intact. For these studies, we treated $n k x 2.2 a$ :gfp;olig2:dsred embryos with DAPT from 48 to $72 \mathrm{hpf}$, then transferred larvae to fresh medium without drug until $6 \mathrm{dpf}$. We used DAPT treatment to block perineurial glial migration from the spinal cord as opposed to genetic manipulation because the heat shock required for genetic manipulation resulted in larvae that were extremely unhealthy by $6 \mathrm{dpf}$ (data not shown). Similar to our previous studies (Binari et al., 2013), we observed that perineurial glia were completely absent from spinal motor nerves at $6 \mathrm{dpf}$ in larvae that had been previously treated with DAPT (Fig. 4D). We then transected rostral motor nerves in these larvae and imaged at $48 \mathrm{hpt}$ to assess axon regrowth. All transections created injury gaps that were $<7$ $\mu \mathrm{m}$, which in vehicle control animals always resulted in the formation of perineurial bridges and either full or moderate regrowth (Fig. $4 A, B, E$ ). In contrast, in DAPT-treated larvae that lacked perineurial glia along motor axons and therefore perineurial bridges $(n=13)$, we observed that nearly half $(46 \%)$ of all transections resulted in no axon regrowth (Fig. $4 D, E$ ). Col- lectively, these data demonstrate that axon regrowth is hindered in the absence of perineurial glial bridges, and we conclude that this is consistent with the hypothesis that perineurial glial bridges are essential for full axon regrowth.

Perineurial glia, Schwann cells, and macrophages appear to coordinate their behaviors during axon degeneration Successful peripheral nerve regeneration requires the efforts of multiple cell types, including macrophages and Schwann cells. Because perineurial glia play a role during injury as well, we sought to investigate whether they coordinated their injury response with these other cell types. Previous studies demonstrate that, shortly after nerve damage, macrophages are recruited to injured lesions and play a major role in debris clearance (Perry et al., 1987; Griffin et al., 1992; Vargas and Barres, 2007; Rosenberg et al., 2012). To view macrophage activity after injury, we transected and time-lapse imaged the rostral nerve in $6 \mathrm{dpf}$ mpeg $1: g f p$; olig2:dsred larvae $(n=12)$, in which mpeg1 regulatory sequences drive cytosolic EGFP specifically in macrophages (Ellett et al., 
mpeg1:gfp;olig2:dsred
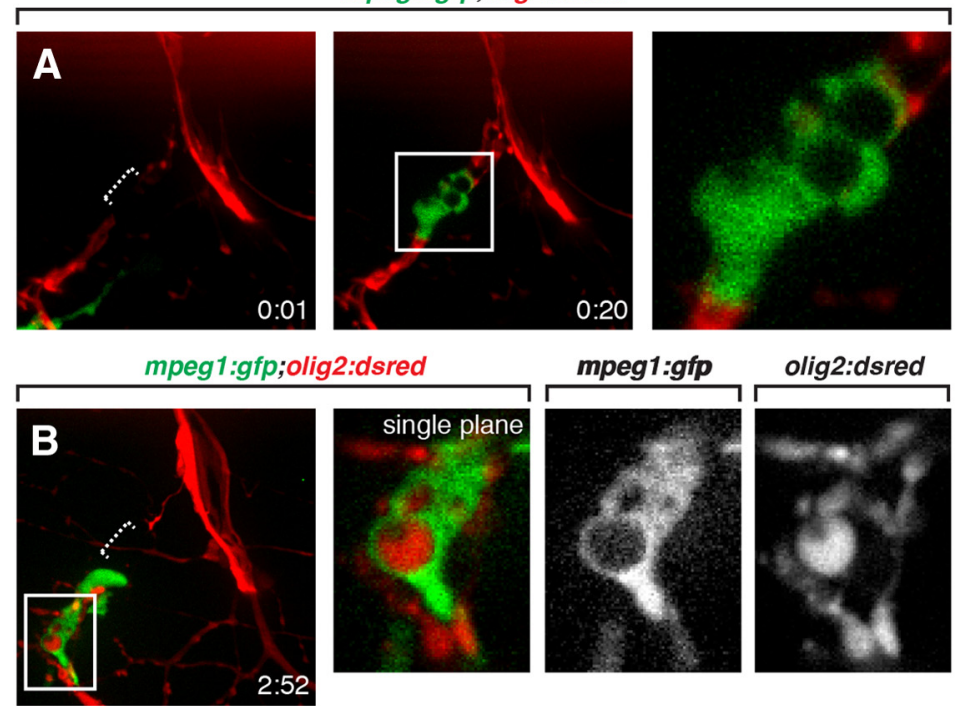

mpeg1:gfp;nbt:dsred;
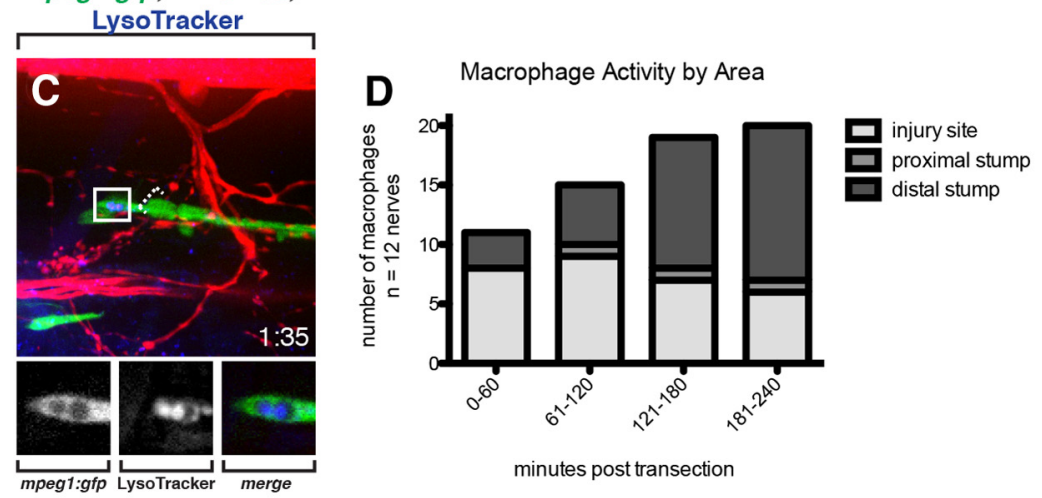

nkx2.2a:gfp;mpeg1:gfp;olig2:dsred
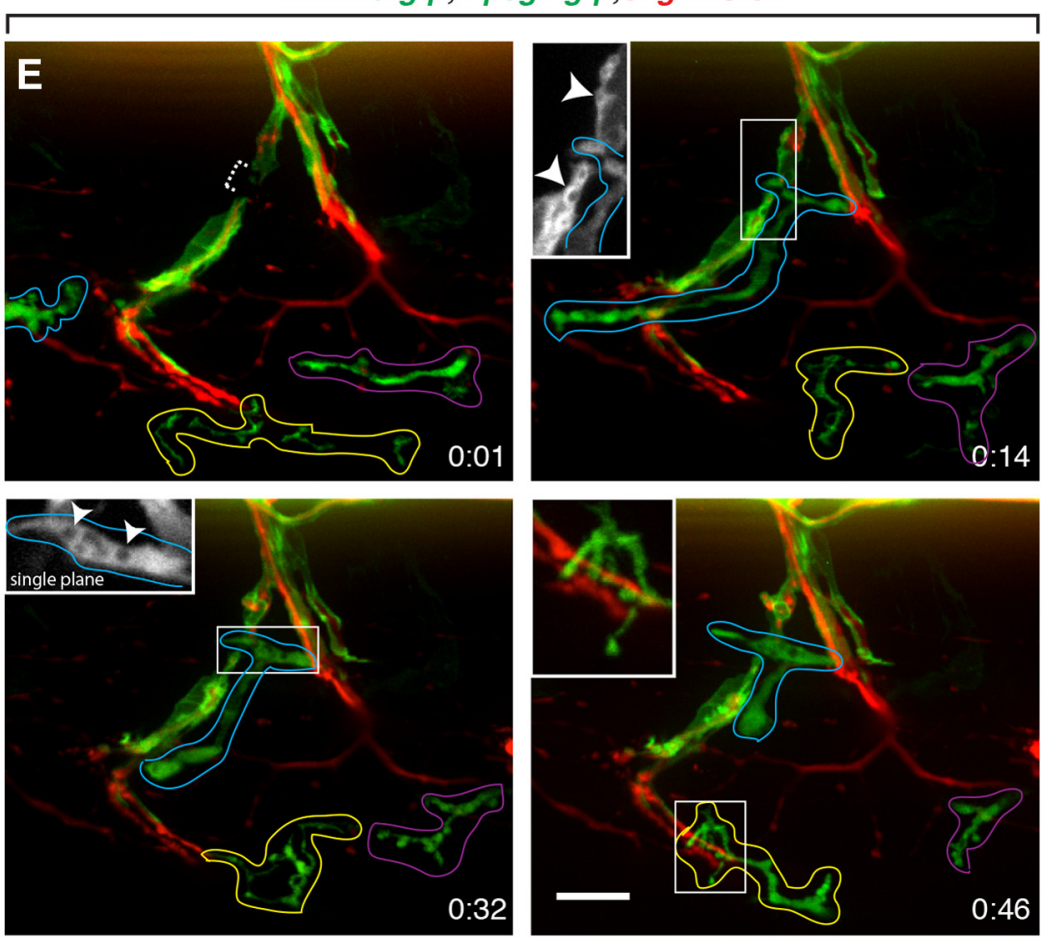

Figure 5. Perineurial glia spatially coordinate early debris clearance with macrophages. Frames captured from time-lapse movies beginning at $1 \mathrm{mpt}$ with dorsal to the top and anterior to the left. mpt is indicated in bottom right corner of each image
2011). In 10 of 12 cases, macrophages were recruited to injured nerves within 4 hpt (the end of the imaging time period), and vesicles were observed within these macrophages at both the injury site and along the distal stump (Fig. 5A,B). Axonal debris was often present within vesicles along the distal stump as axons underwent Wallerian degeneration (Fig. $5 B)$, and LysoTracker staining indicated that these vesicles represent phagocytic activity (Fig. 5C). When we tracked the migration of individual macrophages over time, we found that, along 12 nerves, 21 total cells responded to the injuries. Interestingly, these cells appeared to clear debris primarily at the injury site and along the distal stump (Fig. $5 A, B, D$ ) and rarely extended processes along the proximal stump (Fig. 5D). Given our earlier data that showed perineurial glia phagocytize debris along the proximal stump, these data led us to hypothesize that macrophage and perineurial clearing activity may be spatially coordinated after injury.

To investigate how perineurial glia and macrophages coordinate their behaviors after injury, we transected nerves and time-lapse imaged $6 \mathrm{dpf} n k \times 2.2 a$ :gfp;olig2: dsred;mpeg1:gfp larvae $(n=4)$, which allowed us to visualize axons, perineurial glia, and macrophages simultaneously. Although perineurial glia and macrophages were both labeled with GFP, they were readily distinguishable based on fluorescent protein localization (membrane vs cytosolic), morphology, and behavior.

\footnotetext{
dotted brackets indicate the injury gaps. $\boldsymbol{A}, \boldsymbol{B}$, Representative frames captured from time-lapse movies of $6 \mathrm{dpf}$ mpeg 1:gfp; oligz:dsred larvae show a macrophage containing vesicles at the injury gap $(\boldsymbol{A})$ and a macrophage with vesicles containing axonal debris along the distal stump $(\boldsymbol{B})$. C, Frame captured from a time-lapse movie of a $4 \mathrm{dpf}$ mpeg1:gfp;nbt:dsred larva stained with LysoTracker Deep Red dye shows LysoTracker staining within macrophage vesicles near the injury gap. $\boldsymbol{D}$, Quantification of macrophage activity along various areas of the nerve. Data were taken from time-lapse movies of $6 \mathrm{dpf}$ mpeg1:gfp;olig2:dsred larvae. Twenty-one macrophages from 12 nerves were individually tracked, and the total number of cells in each area was assessed over $240 \mathrm{mpt}$ and binned by time. $\boldsymbol{E}$, Representative frames captured from a time-lapse movie of a $6 \mathrm{dpf} n$ kx2.2a:gfp;mpeg1:gfp;olig2:dsred larvae. Individual macrophages are outlined to distinguish from perineurial glia and to allow tracking throughout the sequence. By $14 \mathrm{mpt}$, perineurial glia began to phagocytize debris along the degenerating stumps and a macrophage (blue outline) arrived at the injury gap. At $32 \mathrm{mpt}$, vesicles (arrowheads) appeared within the macrophage; and by $46 \mathrm{mpt}$, an additional macrophage (yellow outline) appeared to contact distal stump axons. A third macrophage (purple outline) did not respond to the injury during the imaging window. White boxes represent region of magnified inset. Scale bar, $10 \mu \mathrm{m}$.
} 
As described above (Figs. 2 and 3; Movie 1), our time-lapse imaging data revealed that transection induced perineurial glia to extend highly motile membrane processes toward injury sites and form phagocytic vesicles (Fig. $5 E$ ). These phagocytic vesicles populated perineurial glial membranes along both stumps immediately adjacent to the injury site and were particularly numerous along the proximal stump, which undergoes rapid AAD immediately after injury (Fig. 5E). Interestingly, these perineurial responses were usually observed before the arrival of macrophages, and the mean response time for perineurial glia was significantly shorter and less variable than for macrophages (perineurial glial mean response time: $8.636 \pm 0.09749 \mathrm{mpt}, n=11$; macrophage mean arrival time: $45.0 \pm 14.43 \mathrm{mpt}, n=9, p=0.0120$ ). Whereas perineurial glial vesicles appeared along the stumps undergoing $\mathrm{AAD}$, macrophages were usually attracted directly to the injury gap, and vesicles within these macrophages indicated they were clearing debris primarily in the gap zone (Fig. $5 E$ ). We also observed that additional macrophages were often recruited to the distal stump as axons fragmented during Wallerian degeneration (Fig. 5E), and we frequently observed vesicles in perineurial glia along the distal stump around this time as well (Fig. 3). These data demonstrate that perineurial glia respond to transections and begin debris clearance more quickly than macrophages. These data also show that these two cell types initially focus on clearing debris within distinct zones, with perineurial glia focusing on the degenerating stumps and macrophages focusing on the injury gap, but work together in similar areas during later stages of degeneration. This is consistent with the hypothesis that perineurial glia and macrophages spatially coordinate debris clearance.

In addition to macrophages, Schwann cells also play an important role in peripheral degeneration and regeneration by phagocytizing myelin and forming cellular columns that span injury gaps to help guide regenerating axons (Perry et al., 1995; Parrinello et al., 2010; Webber and Zochodne, 2010; Gaudet et al., 2011; Brosius Lutz and Barres, 2014). Because Schwann cells and perineurial glia coordinate their behaviors and require each other during development (Kucenas et al., 2008; Binari et al., 2013; Clark et al., 2014), we hypothesized that these cell types may coordinate again after nerve injury. To test this hypothesis, we transected nerves and time-lapse imaged $n k \times 2.2 a$ :gfp;sox10:eos larvae, which allowed visualization of perineurial glia and Schwann cells simultaneously. The sox10:eos transgene uses regulatory elements from the sox 10 gene to drive expression a cytosolic, photo-convertible Eos protein in Schwann cells. Mature Eos protein, when exposed to UV light, shifts its emission from a green fluorescent state $(516 \mathrm{~nm})$ to a red fluorescent state $(581$ $\mathrm{nm}$ ). By exposing these larvae to UV light, we can easily distinguish Schwann cells (red after UV light exposure) from perineurial glia (green after UV light exposure). For these studies, we exposed larvae to UV light before time-lapse imaging and subsequently reexposed the larvae every 20 min throughout the course of imaging to convert any newly produced green Eos so that Schwann cells would remain completely red. Similar to our results above (Fig. 2), we observed several phagocytic vesicles within perineurial membranes along the proximal stump within 15-20 mpt (data not shown). We also observed vesicles within sox $10^{+}$cells on the proximal stump (data not shown), and later along the distal stump (Fig. 6A). Importantly, these vesicles labeled with LysoTracker, suggesting they represent phagocytic activity (Fig. 6A). These data indicate that Schwann cells phagocytize debris with similar temporal and spatial dynamics as perineurial glia. As we continued imaging, perineurial glia bridged the injury gap during the $4 \mathrm{~h}$ imaging window we used after transection (Fig. 6B,C). Schwann cells, however, extended processes slightly toward the injury site but never bridged the injury gap during the imaging time-period $(n=4)$ (Fig. $6 B, C)$. These data demonstrate that perineurial glia and Schwann cells both phagocytize debris after injury and that perineurial glia bridge injury gaps before Schwann cells. This is consistent with the idea that perineurial glia form an initial tissue bridge across the injury gap, with Schwann cells and axons traversing the gap later.

\section{Perineurial glia require Schwann cells after nerve injury}

Interactions between cell types are critical for ultrastructural and functional nerve regeneration (Parrinello et al., 2010; Napoli et al., 2012). Therefore, we sought to identify which cell types, if any, were required for the perineurial glial response to injury. To investigate this, we used a combination of time-lapse imaging, mutant analysis, and cell-type specific perturbation. We first considered the possibility that perineurial glia respond to signals released from neighboring, damaged perineurial glial cells. To test this hypothesis, we transected motor axon tracts in $n k x 2.2 a$ : gfp;ntb:dsred larvae that were not ensheathed by perineurial glia and assessed the response of nearby perineurial glial cells. These experiments were performed in $4 \mathrm{dpf}$ larvae, as not all spinal motor axon tracts have become fully ensheathed by $n k x 2.2 a^{+}$ perineurial glia yet at this stage, providing an ideal situation to test this hypothesis. Importantly, perineurial glia respond to nerve transection by phagocytizing debris and bridging injury gaps in a manner similar to what we describe at $6 \mathrm{dpf}$ (compare Fig. 7A with Fig. 2). Therefore, using $4 \mathrm{dpf}$ larvae, we transected unensheathed axons $\sim 10-15 \mu \mathrm{m}$ away from neighboring perineurial glia and assessed the response of these neighbors to the injury $(n=7)$. Immediately after injury, we observed that perineurial cells along neighboring, uninjured axon tracts rapidly extended processes toward the injury site and formed phagocytic vesicles by $15 \mathrm{mpt}$ (Fig. $7 \mathrm{~B}$; Movie 2). This response time was similar to our previous findings along fully ensheathed tracts in 6 dpf larvae (mean response time for $4 \mathrm{dpf}, 9.286 \pm 2.296 \mathrm{mpt}, n=$ $7 ; 6 \mathrm{dpf}, 8.636 \pm 0.9749 \mathrm{mpt}, n=11$ ), suggesting that perineurial glia respond to injuries with similar temporal dynamics regardless of ensheathment. To independently test the possibility that perineurial glia do not simply respond to axotomies because they sense damage in neighboring cells, we transected dorsal root ganglia sensory axons in $6 \mathrm{dpf} n k x 2.2 a$ :gfp; $n t b$ :dsred larvae, as they are not ensheathed by $n k x 2.2 a^{+}$perineurial glia (unpublished data). In these instances, we again observed neighboring perineurial glia extend processes onto the unensheathed sensory axons and phagocytize debris (Fig. 7C). Collectively, these data are consistent with the hypothesis that the perineurial glia do not respond to nerve injury using an autocrine mechanism. Instead, we hypothesize that perineurial glial activation after injury requires non-perineurial-derived cues. Interestingly, this is distinct from their bridging behavior, which we hypothesize is mediated by perineurial-perineurial interactions.

Another potential source of factors that could elicit perineurial behavior after injury is macrophages. Macrophages that respond to injury sites release a variety of cytokines (Leskovar et al., 2000), which could play a role in recruiting perineurial glia to injury sites or stimulating their phagocytic activity. To test this hypothesis, we transected nerves in larvae that lacked macrophages and assessed the perineurial glial response. To create larvae that completely lacked macrophages, we prevented macrophage specification by injecting single-cell embryos with 

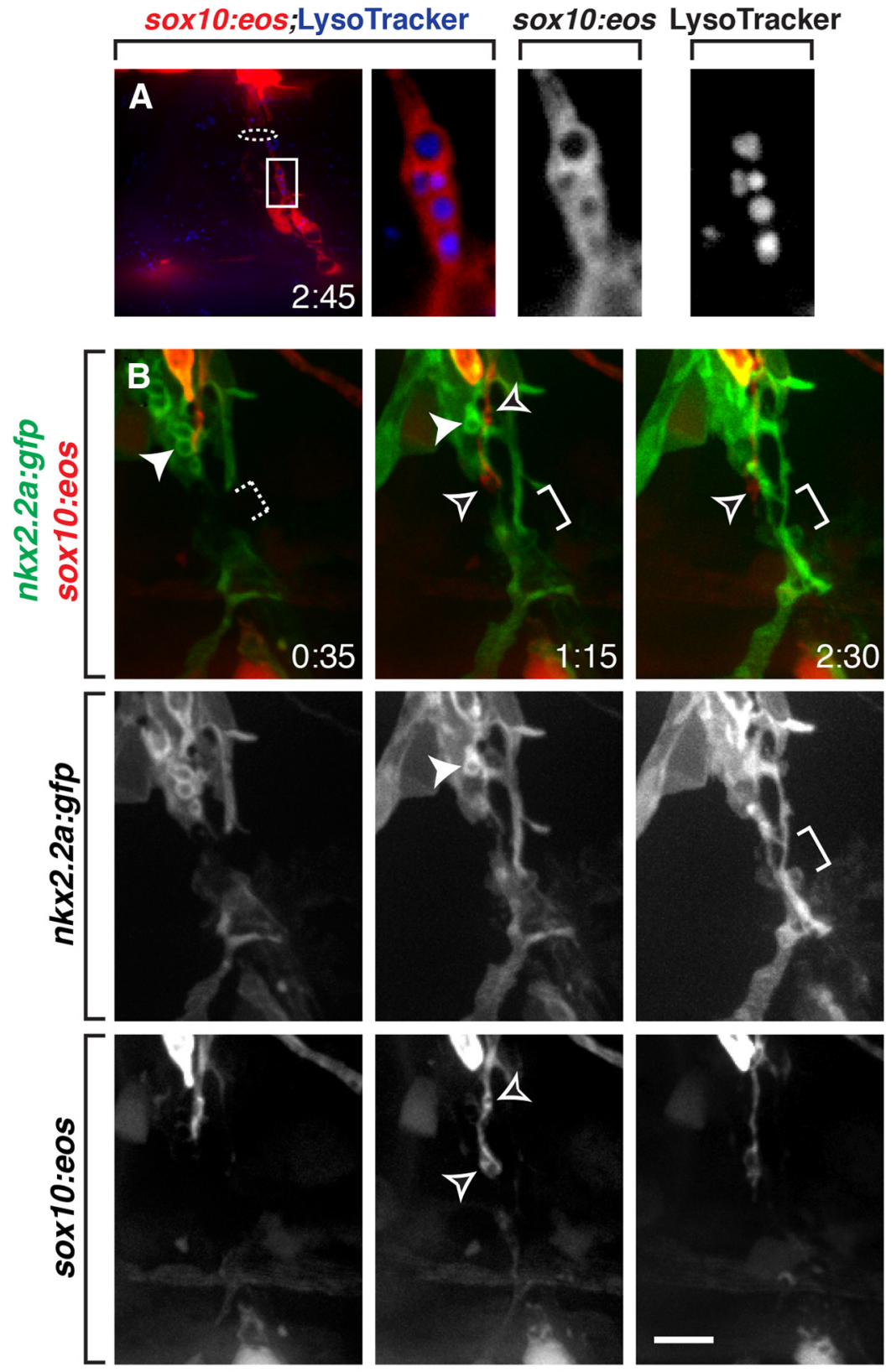

C

Injury Gap Bridging

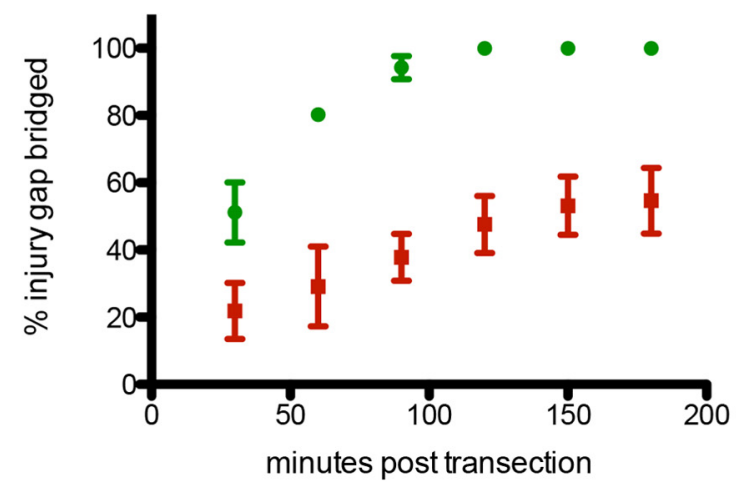

Figure 6. Perineurial glia bridge injury gaps before Schwann cells. Frames captured from time-lapse movies are displayed with dorsal to the top and anterior to the left. mpt is indicated in bottom right corner of each image. Dotted ellipse indicates ablated ROl; dotted bracket indicates injury gap. $\boldsymbol{A}$, Frames captured from a time-lapse movie of a $4 \mathrm{dpf}$ sox 10:eos larva stained with LysoTracker Deep Red shows LysoTracker staining within sox10:eos ${ }^{+}$vesicles. $\boldsymbol{B}$, Frames captured from a time-lapse movie of a $6 \mathrm{dpf} n k \times 2.2 a$ : gfp;sox10:eos larva. By $35 \mathrm{mpt}$, perineurial glia had phagocytic vesicles (arrowheads) but had not yet bridged the entire injury gap an MO against the spilb gene, which encodes a transcription factor essential for myeloid differentiation in zebrafish (Bukrinsky et al., 2009). As previously described, spilb MO-injected fish lacked myeloid cells (Rhodes et al., 2005; Villegas et al., 2012) and were morphologically indistinguishable from control larvae at 6 dpf (data not shown). We performed our nerve transections in $n k x 2.2 a$ :gfp;olig2: dsred;spilb:gfp larvae. The spilb:gfp transgene, which labels leukocytes, allowed us to verify that no macrophages were present during our studies. After transection in spilb morphant larvae $(n=5)$, we observed that axonal debris created during AAD of the stumps appeared to be cleared normally, whereas debris generated by Wallerian degenerating axons along the distal stump was cleared more slowly and often remained at the end of the $4 \mathrm{~h}$ imaging window (data not shown). This is in contrast to control larvae, where the majority of axonal debris was cleared almost immediately after fragmentation (before $4 \mathrm{hpt}$ ) (Fig. 2). Interestingly, the perineurial glial response to transection in spilb morphants was indistinguishable from noninjected control larvae, and perineurial cells extended processes toward the injury site, phagocytized debris, and bridged the injury gap with the same temporal dynamics we describe above (compare Fig. $7 D$ with Fig. 2). We interpret these data to mean that perineurial glia do not require signals from macrophages for their response to injury, and this is consistent with our earlier data, which showed that perineurial glia usually respond to injuries before the arrival of macrophages. These data also demonstrate that perineurial glia and other phagocytes, such as Schwann cells, are sufficient to clear debris created during $\mathrm{AAD}$, but not Wallerian degeneration of the distal stump.

Given that perineurial glia respond normally to transections along unensheathed axons and in larvae lacking macrophages, we next investigated the possibility that axon fragmentation and degeneration are responsible for eliciting perineur-

\section{$\leftarrow$}

(dotted bracket). At $1 \mathrm{~h} 15 \mathrm{mpt}$, vesicles were present within both Schwann cells (open arrowheads) and perineurial glia, and perineurial glia had bridged the injury gap (solid bracket). At $2 \mathrm{~h} 30 \mathrm{mpt}$, perineurial glia remained across the injury gap but the Schwann cell never bridged. C, Quantification of injury gap bridging by $n k \times 2.2 a^{+}$and sox $10^{+}$processes $(n=4)$. The percentage of the initial injury gap that was bridged by each type of process was measured every $30 \mathrm{~min} . n k \times 2.2 a^{+}$processes bridged $100 \%$ of the injury gap (a complete bridge) by $120 \mathrm{mpt}$, whereas so $\times 10^{+}$processes did not. Scale bar, $5 \mu \mathrm{m}$. 


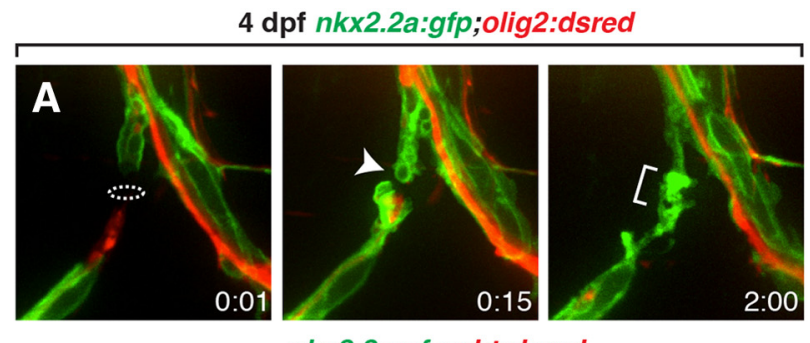

nkx2.2a:gfp;nbt:dsred
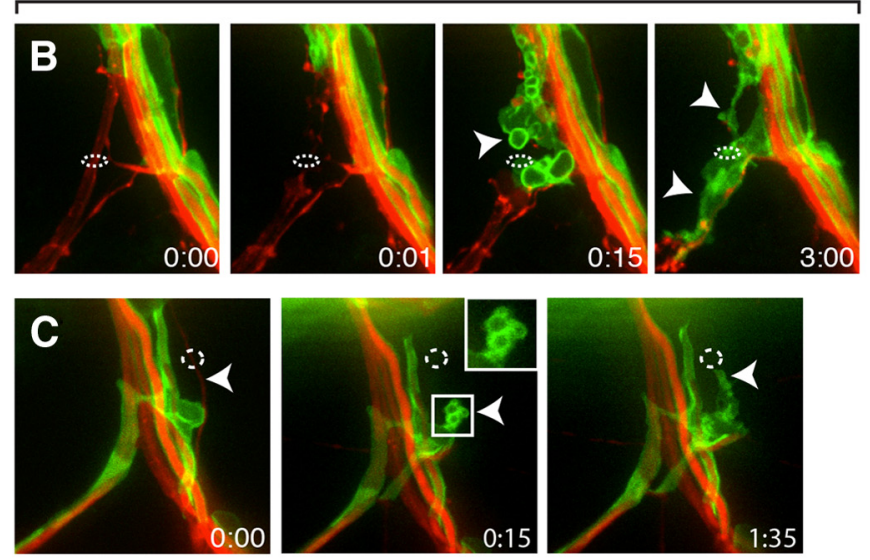

nkx2.2a:gfp;olig2:dsred;spi1b:gfp;spi1b-MO

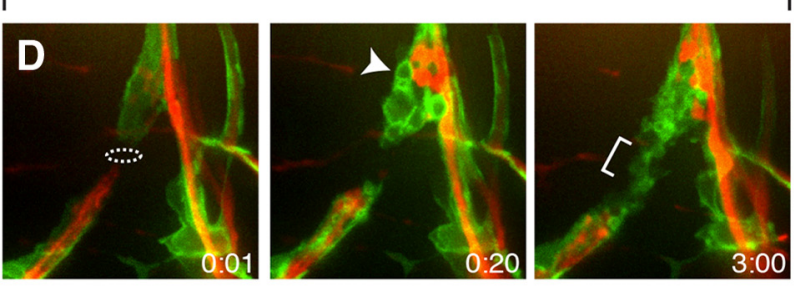

nkx2.2a:gfp;olig2:dsred;mnx1:w/ds-gfp
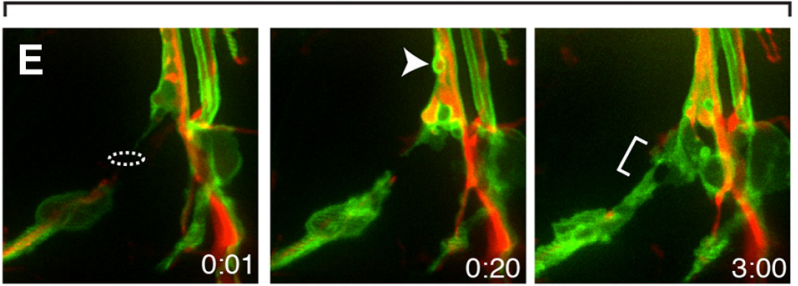
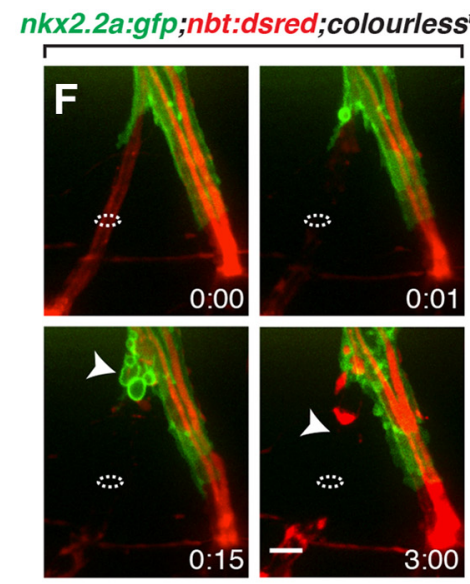

G Perineurial Response Time

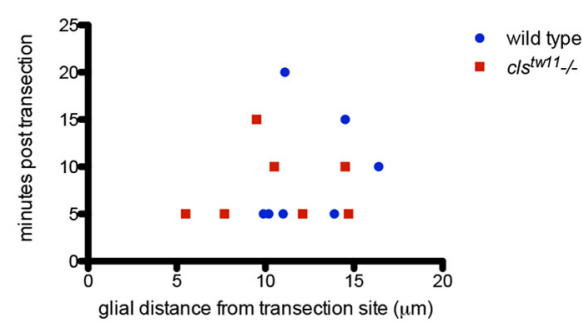

H

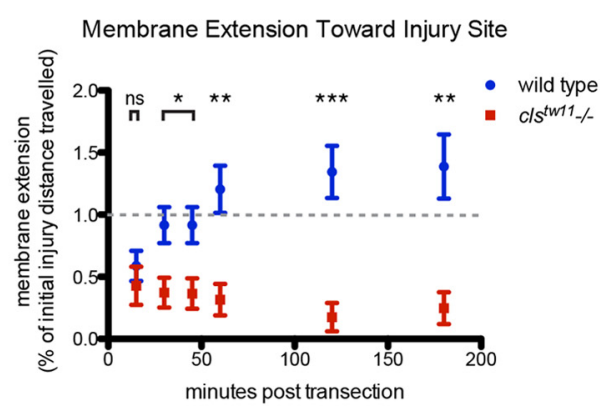

Figure 7. Perineurial glia require Schwann cells, but not macrophages or Wallerian degeneration, for their response to injury. All images are frames captured from time-lapse movies of larvae beginning at $1 \mathrm{mpt}$ with dorsal to the top and anterior to the left. mpt is indicated in bottom right corner of each image. Dotted ellipses indicate ablated ROIs. $A$, The rostral motor nerve was transected in 4 dpf $n k x 2.2 a$ :gfp;olig2:dsred larvae. Perineurial glia responded by phagocytizing debris (arrowhead) and bridging the injury gap (bracket) similarly as in 6 dpf larvae. B, C, Unensheathed nerve

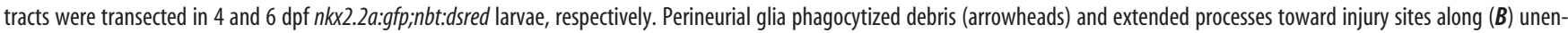
sheathed motor nerves and $(\boldsymbol{C})$ sensory nerves in a manner indistinguishable from fully ensheathed nerves. $\boldsymbol{D}$, Rostral motor nerves were transected in a $6 \mathrm{dpf} n \mathrm{kx} 2.2 \mathrm{a}$ :gfp;olig2:dsred;spi7b:gfp spi1b M0-injected larva that lacked macrophages. Perineurial glia responded similarly to noninjected controls by phagocytizing debris (arrowhead) and bridging the injury gap (bracket). $E$, Rostral motor nerves were transected in a $6 \mathrm{dpf} n k \times 2.2 a$ :gfp;olig2:dsred; $m n \times 1$ :wlds-gfp larva where Wallerian degeneration was significantly delayed. Again, perineurial glia responded similarly to controls by phagocytizing debris (arrowhead) and bridging the injury gap (bracket). $F$, Perineurial glia phagocytized debris (arrowhead) but did not extend processes toward the injury site in a 4 dpf

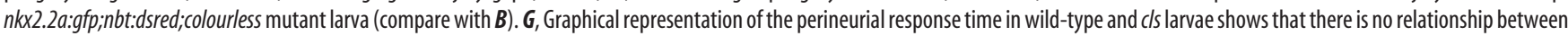
the distance of glial cells from the transection site and response time in these experiments. The number of minutes post transection it took perineurial glia to begin extending processes toward injuries or phagocytize debris was plotted by the initial distance between the glial cells and the transection site. $\boldsymbol{H}$, Quantification of the extension of perineurial processes toward transection sites in wild-type and cls larvae shows that perineurial glia extend processes significantly further in wild-type. Because the initial distance between the injury site and glial cells varied slightly with each trial, membrane extension was plotted as a percentage of the initial injury distance traveled, where values $>1$ represent processes that have extended beyond the initial injury site. $p$ values for each time point assessed are as follows: $15 \mathrm{mpt}, p=0.43966$ (ns, not significant); $30 \mathrm{mpt}, p=0.01204\left(^{*}\right) ; 45 \mathrm{mpt}, p=0.02885\left({ }^{*}\right) ; 60 \mathrm{mpt}, p=0.00159\left(^{* *}\right) ; 120 \mathrm{mpt}, p=0.00037\left({ }^{* * *}\right) ; 180 \mathrm{mpt}$, $\left.p=0.00268^{* *}\right)$. Scale bar, $5 \mu \mathrm{m}$.

ial glial activity after injury. To test this hypothesis, we transected nerves in $m n x: W l d^{s}-g f p$ larvae, in which motor neurons express the Wallerian degeneration Slow $\left(\mathrm{Wld}^{\mathrm{s}}\right)$ protein (Rosenberg et al., 2012). Expression of Wld ${ }^{s}$ significantly delays Wallerian degeneration through a conserved axon-intrinsic mechanism
(Lunn et al., 1989; Adalbert et al., 2005; MacDonald et al., 2006; Martin et al., 2010; Rosenberg et al., 2012) and has been shown to suppress aspects of glial activation in mouse and Drosophila (Lunn et al., 1989; MacDonald et al., 2006). Surprisingly, after axotomy in these mutants $(n=6)$, perineurial glia phagocytized 


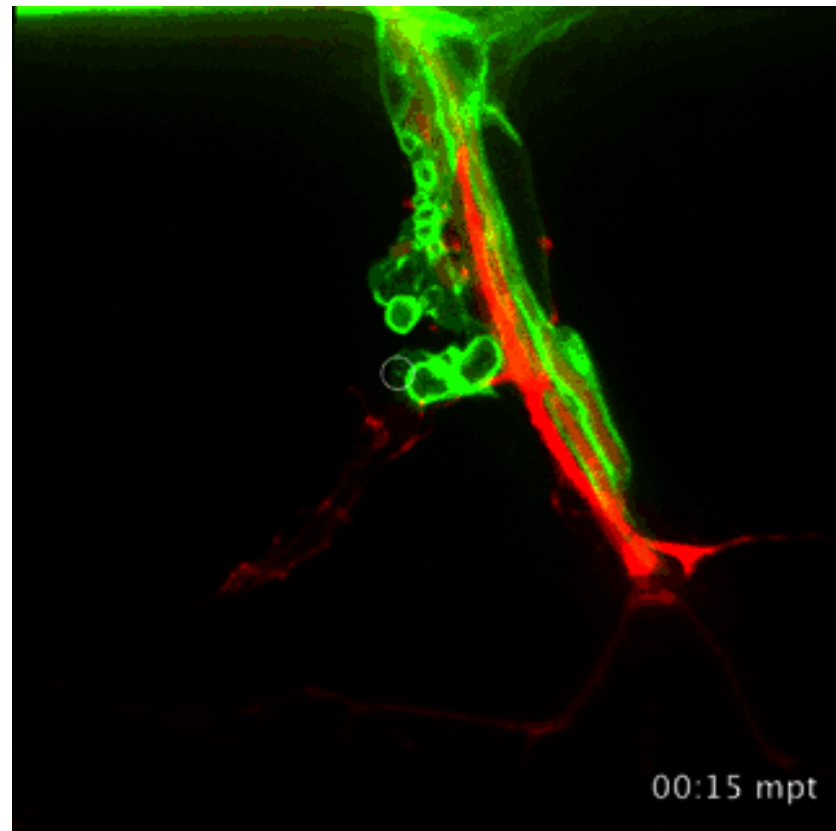

Movie 2. Perineurial glia respond to transections along unensheathed axons. Three hour time-lapse movie of a $4 \mathrm{dpf} n k x 2.2 a$ :gfp;nbt:dsred larva beginning at $1 \mathrm{mpt}$ with dorsal to the top and anterior to the left. Images were captured in 5 min intervals, and mpt is indicated in bottom right corner of each frame. White circle represents the approximate ablated ROI. Perineurial glial processes are attracted to the injury site and phagocytize debris.

debris and bridged injuries in a manner that was indistinguishable from control larvae (compare Fig. 7E with Fig. 2), suggesting that Wallerian degeneration is not necessary for perineurial glia to respond to injuries in our assay.

Finally, we investigated the possibility that Schwann cells are required for the perineurial glial injury response. Nerve injury induces Schwann cells to release cytokines and growth factors that are responsible for recruiting macrophages and promoting axon regrowth (Chen et al., 2007; Vargas and Barres, 2007; Napoli et al., 2012; Brosius Lutz and Barres, 2014). Additionally, previous studies demonstrate that Schwann cells communicate reciprocally with perineurial glia during development and that development of either cell type is disrupted in the absence of the other (Kucenas et al., 2008; Binari et al., 2013). This raised the intriguing possibility that signals released by Schwann cells could be responsible for eliciting perineurial glial responses after injury. To investigate this hypothesis, we transected nerves in $4 \mathrm{dpf}$ $n k x 2.2 a$ :gfp; $n t b:$ dsred;colourless ${ }^{\text {tw1 }}{ }^{(\mathrm{cls})}$ mutant larvae, which are deficient for sox10 and lack motor nerve-associated Schwann cells (Dutton et al., 2001). Although oligodendrocyte precursor cells exit the spinal cord in $c l s$ larvae, they do not ensheath axons and die before $4 \mathrm{dpf}$ (Kucenas et al., 2009). However, even in the absence of all other peripheral glia, we found that some perineurial glial cells still migrated from the spinal cord into the periphery and remained associated with motor nerves after oligodendrocyte precursor cells died (Fig. $7 F$ ). Although perineurial glia were present, they were sparse and did not form contiguous sheaths (Fig. $7 F$ ). Therefore, we transected unensheathed axons to test the ability of neighboring perineurial glial cells in $4 \mathrm{dpf} c l s$ larvae to respond to injury $(n=8)$. As in wild-type, transections were made $\sim 10-15 \mu \mathrm{m}$ away from the nearest perineurial glial cell (average distance between perineurial glia and transection site was $12.43 \pm 0.9436, n=7$ in wild-type and $10.89 \pm 1.144, n=8$ for cls, not significant), and there was no relationship between the

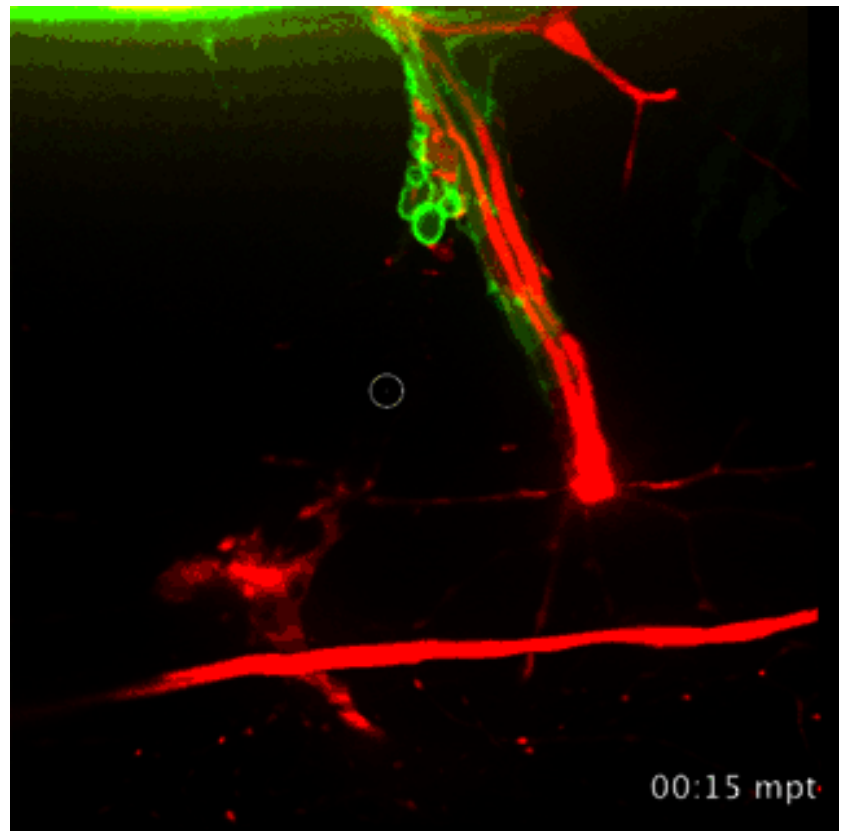

Movie 3. Perineurial processes are not attracted to injury sites in colourless ${ }^{t w 11}$ mutants Three hour time-lapse movie of a $4 \mathrm{dpf} n k \times 2.2 a$ :gfp;nbt:dsred;colourless ${ }^{t w 11}$ larva beginning at $1 \mathrm{mpt}$ with dorsal to the top and anterior to the left. Images were captured in $5 \mathrm{~min}$ intervals, and mpt is indicated in bottom right corner of each frame. White circle represents the approximate ablated ROI. Perineurial glia do not extend significant processes toward the injury site but do form phagocytic vesicles.

distance from transection site and the perineurial response time for either genotype (Fig. $7 G$ ). Unlike wild-type larvae (Fig. 7B; Movie 2), we observed that transection in $\mathrm{cls}$ larvae induced only minimal extension of perineurial processes toward injury sites (Fig. 7 F, H; Movie 3). However, we still observed phagocytic vesicles along the proximal stump as it degenerated in all cases for both $c l s(n=8)$ and wild-type larvae $(n=7)$ (Fig. 7 B, F; Movie $2,3)$. These data demonstrate that perineurial glia are significantly less attracted to injury sites in the absence of Schwann cells but remain competent to phagocytize debris. Together, these studies are consistent with the hypothesis that perineurial glial behaviors after nerve injury are not dependent on signals from macrophages or degenerating axons. Instead, they appear to require interactions with Schwann cells, much like they do during development.

\section{Discussion}

Peripheral nerve regeneration has long been a subject of intense study. However, the role of perineurial glia in this process has remained somewhat elusive. Some have hypothesized that perineurial cells may be responsible for creating the first bridge across the injury gap (Scaravilli, 1984; Schroder et al., 1993), and others have shown that the perineurium dramatically changes its structure along proximal and distal stumps after transection (Thomas and Jones, 1967; Morris et al., 1972). Here, we provide the first detailed account of dynamic perineurial glial behaviors after nerve transection. We show that spinal motor root axon transection induces rapid changes in the membrane activity of perineurial glia, with cells immediately adjacent to the injury extending highly motile processes toward the transected area and phagocytizing debris. Perineurial glial membranes then bridge injury gaps, and we demonstrate that these bridges are essential for guiding axon regrowth (Fig. 8). We also show that perineurial glia do not require signals from other perineurial glia or macro- 
A Intact peripheral nerve pre-injury

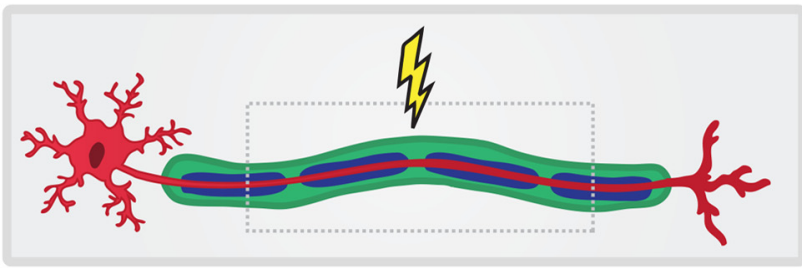

B $0-20 \mathrm{mpt}$ : Axons begin AAD, perineurial glia extend processes toward injury site and phagocytize debris with Schwann cells

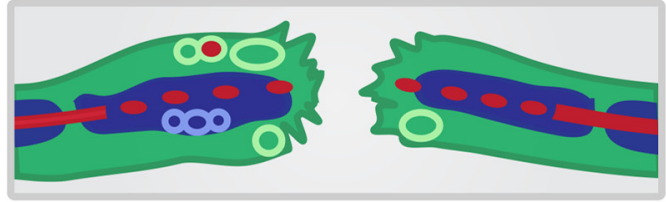

C 20-60 mpt: Macrophages arrive at injury site to clear debris

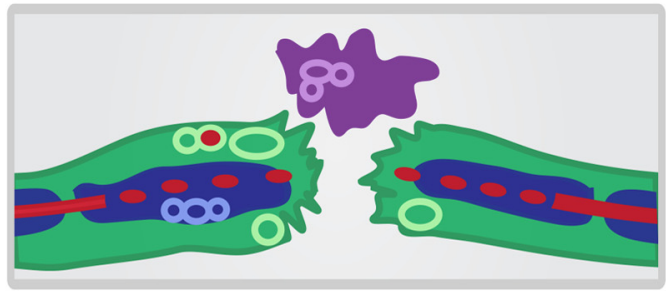

D 30 mpt-3 hpt: Perineurial glia bridge injury gaps, distal axons degenerate, perineurial glia, macrophages, and Schwann cells clear debris

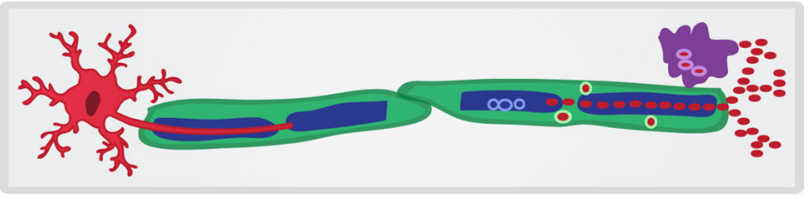

E $3 \mathrm{hpt}-48 \mathrm{hpt}$ : Axons regrow along perineurial membranes

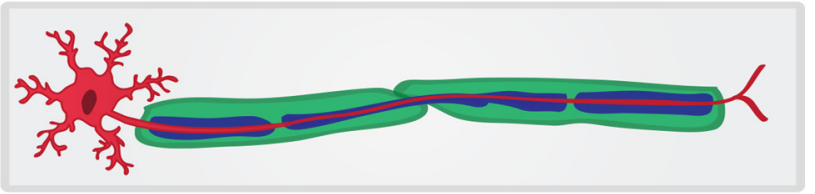

F Absence of perineurial bridges leads to impaired regrowth

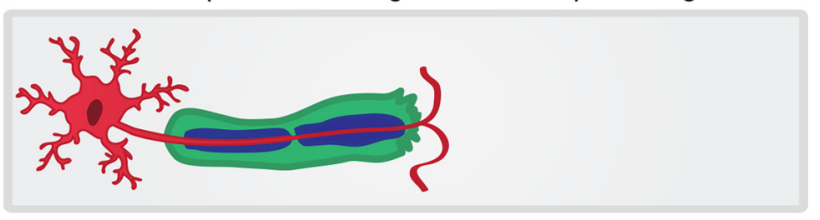

Figure 8. Model of perineurial glial response to motor nerve injury. Depicted timeline is an approximation based on data collected for this manuscript and highlights typical perineurial behaviors. Precise behaviors and response times vary for individual transections. $A$, An intact motor neuron (red) is ensheathed by Schwann cells (blue) and perineurial glia (green). $\boldsymbol{B}$, Between 0 and $20 \mathrm{mpt}$, axons near the injury sites begin AAD and perineurial glia extend membrane processes into the injury site and phagocytize debris (green circles) along with Schwann cells (blue circles). C, Between 20 and $60 \mathrm{mpt}$, macrophages (purple) arrive at the injury site and aid in debris clearance (purple circles). D, Between $30 \mathrm{mpt}$ and $3 \mathrm{hpt}$, perineurial glia bridge the injury site before axons and Schwann cells. Then distal axons fragment and debris is cleared by perineurial glia, macrophages, and Schwann cells. $\boldsymbol{E}$, From 3 to $48 \mathrm{hpt}$, axons regenerate along perineurial bridges. $\boldsymbol{F}$, The absence of perineurial bridges results in impaired axon regrowth. phages for this response, and they respond normally even in the absence of Wallerian degeneration. Interestingly, perineurial glia do require Schwann cells for specific aspects of their injury response, much like they do during development. These data shed light on novel behaviors of perineurial glia after motor nerve injury and raise the intriguing possibility that they may be involved in other degenerative diseases of the PNS as well.

\section{Perineurial glial phagocytic behavior}

Macrophages and Schwann cells are the primary cells involved in debris clearance after nerve injury in the PNS. Schwann cells begin phagocytosis of myelin immediately after injury, and macrophages infiltrate nerves soon after (Liu et al., 1995; Perry et al., 1995; Hirata and Kawabuchi, 2002; Vargas and Barres, 2007). Our data support these findings and demonstrate that perineurial glia are phagocytic and aid in debris clearance as well. These data are fitting with several electron microscopy studies that noted the presence of vesicles within perineurial cells along the proximal stump of transected mouse sciatic nerves (Morris et al., 1972; Röyttä et al., 1987) and within the cells that form the initial bridge between transected stumps (Scaravilli, 1984). However, despite these observations, the authors stopped short of concluding that perineurial glia are phagocytic, as it is very difficult to determine the identity and origin of individual cells by electron microscopy after transection. Using in vivo imaging in a live system that allows for the specific and continuous visualization of perineurial glia, we demonstrate that perineurial glia are phagocytic.

Temporally, our data reveal that perineurial glial phagocytic vesicles are particularly abundant along the proximal stump immediately after injury, which is consistent with our data showing that proximal stump AAD occurs more rapidly than distal stump $\mathrm{AAD}$. This is in contrast to mammalian systems, where AAD is reported to occur symmetrically along both stumps (Kerschensteiner et al., 2005). Spatially, our studies reveal that, whereas perineurial glia focus on clearing debris along the degenerating stumps immediately after injury, macrophages tend to focus initially on the injury gap. These data are consistent with the hypothesis that macrophages and perineurial glia may coordinate debris clearance in different areas and raise the intriguing possibility that distinct phagocytic populations may selectively clear specific debris. In contrast, our studies showed that Schwann cell vesicles formed along the proximal stump shortly after injury, and later along the distal stump, similar to perineurial glia. However, it is still possible that perineurial glia and Schwann cells phagocytize different types of debris in these regions. In the future, investigations into (1) how debris clearance is coordinated between perineurial glia, Schwann cells, and macrophages and (2) the molecular mechanisms that drive perineurial glial phagocytosis will produce a more complete picture of nerve degeneration.

\section{Perineurial glial bridges are required for regeneration}

Previous studies in mammalian systems demonstrate that, after sciatic nerve transection, a tissue bridge forms connecting the proximal and distal stumps, which axons and Schwann cells use while regenerating (McDonald and Zochodne, 2003; McDonald et al., 2006). The precise importance of this initial tissue bridge and the origin of the cells that construct it are not well understood, although several studies have proposed that this bridge is formed by perineurial cells (Scaravilli, 1984; Schroder et al., 1993). Parrinello et al. (2010) described that fibroblasts within this bridge are required to direct the formation of Schwann cell bands and therefore affect axon regrowth. In a recent study (Clark et al., 2014), we demonstrate that a subset of mammalian 
perineurial cells express $N k x 2.2$ and are CNS-derived, similar to zebrafish, raising the intriguing possibility that the fibroblasts described by Parrinello et al. (2010) may be perineurial glia.

Our data unequivocally show that perineurial glia bridge injury gaps within the first few hours after transection, and this behavior occurs well before regenerating axons or Schwann cells are found in this region. When we tested the requirement of perineurial glial bridges by either eliminating perineurial glia or creating injuries too large to be bridged, axon regrowth was impaired, frequently resulting in no regrowth and aberrant sprouting. Collectively, these data are consistent with the hypothesis that axons regrow along perineurial glial bridges and that these bridges are required for efficient regeneration of the nerve. In our DAPT-treatment studies, we did observe some cases where axons regrew in the absence of perineurial bridges, and it is possible that Schwann cells and/or remaining axon guidance cues were sufficient to direct axon regrowth. We did not assay Schwann cells in these studies because previous work in the laboratory has demonstrated that a lack of perineurial glia due to Notch perturbation results in a deficit of peripheral myelin along spinal motor nerves (Binari et al., 2013). Although we cannot rule out that reduced or improperly differentiated Schwann cells are a factor in our conclusions, there is currently no method available to eliminate perineurial glia without affecting Schwann cell development. Together, our data demonstrate that axon regrowth is most successful when perineurial bridges are formed.

\section{What are the signals that drive perineurial glial behavior after nerve injury?}

Nerve regeneration is a precisely coordinated process requiring communication between multiple cell types, and previous studies have shown that axons, Schwann cells, and macrophages are all capable of releasing factors that affect neighboring cells (Chen et al., 2007; Zochodne, 2012; Klimaschewski et al., 2013). Because we never observed extensive motility in perineurial processes or phagocytosis in the absence of nerve injury, we reasoned that perineurial activation had to be a result of changes to the nerve environment due to transection. Our studies reveal that the initial perineurial glial response to injury is independent of macrophages, degenerating axons, and other perineurial glia. However, although distal axon fragmentation is not required for perineurial responses, we cannot rule out the possibility that signals released by fragmenting axons undergoing $\mathrm{AAD}$, or damaged axons at the injury site, may elicit perineurial behavior.

We have previously demonstrated that perineurial glia and Schwann cells communicate reciprocally during development (Kucenas et al., 2008; Binari et al., 2013), and Schwann cells are known to release a variety of factors in response to injury that affect surrounding cells, including NGF, BDNF, LIF, MCP-1, and TNF $\alpha$ (Vargas and Barres, 2007; Jessen and Mirsky, 2008). Therefore, we hypothesized that these cell populations may communicate after nerve injury. Using mutants where all motor Schwann cells are absent, we observed that perineurial glia were less attracted to injury sites. Although we cannot rule out the possibility that changes in perineurial behavior are the result of disrupted perineurial glial differentiation in these mutants, there is currently no alternative approach to eliminate Schwann cells without perturbing perineurial glia.

Our data are consistent with the hypothesis that Schwann cells may be involved in either attracting perineurial glia to injury sites or that their damage during injury releases factors that lead to perineurial invasion into the injury gap. Interestingly, perineurial glia did form phagocytic vesicles in these studies, suggesting that perineurial attraction and phagocytic behavior are independent activities. This is reminiscent of what is seen in Drosophila, where different signaling pathways mediate glial activation and phagocytosis of debris (Ziegenfuss et al., 2012). This is also consistent with our data showing perineurial glia do not routinely bridge large injury gaps, which suggests that, although perineurial glia can be activated in the absence of perineurial-derived cues, they may still coordinate during bridging. Future studies will focus on elucidating the precise mechanisms by which perineurial glia communicate with other cell types after nerve injury, and determine whether Schwann cell-perineurial glial signaling is reciprocal as it is during development.

In conclusion, we demonstrate that perineurial glia are essential for motor nerve regeneration. Immediately after injury, perineurial processes are rapidly attracted to nerve injuries and aid Schwann cells and macrophages in phagocytizing debris. Perineurial glia then bridge injury gaps before axons and Schwann cells, and these bridges are essential for axon regrowth. Collectively, our work highlights the essential function of perineurial glia in nerve regeneration and provides insight into how these cells can be used to promote better regeneration in nerve injury patients.

\section{References}

Adalbert R, Gillingwater TH, Haley JE, Bridge K, Beirowski B, Berek L, Wagner D, Grumme D, Thomson D, Celik A, Addicks K, Ribchester RR, Coleman MP (2005) A rat model of slow Wallerian degeneration (WldS) with improved preservation of neuromuscular synapses. Eur J Neurosci 21:271-277. CrossRef Medline

Akert K, Sandri C, Weibel ER, Peper K, Moor H (1976) The fine structure of the perineural endothelium. Cell Tissue Res 165:281-295. Medline

Arthur-Farraj PJ, Latouche M, Wilton DK, Quintes S, Chabrol E, Banerjee A, Woodhoo A, Jenkins B, Rahman M, Turmaine M, Wicher GK, Mitter R, Greensmith L, Behrens A, Raivich G, Mirsky R, Jessen KR (2012) c-Jun reprograms Schwann cells of injured nerves to generate a repair cell essential for regeneration. Neuron 75:633-647. CrossRef Medline

Banerjee S, Isaacman-Beck J, Schneider VA, Granato M (2013) A novel role for Lh3 dependent ECM modifications during neural crest cell migration in zebrafish. PLoS One 8:e54609. CrossRef Medline

Binari LA, Lewis GM, Kucenas S (2013) Perineurial glia require notch signaling during motor nerve development but not regeneration. J Neurosci 33:4241-4252. CrossRef Medline

Bourne GH (1968) The structure and function of nervous tissue. New York: Academic.

Brosius Lutz AB, Barres BA (2014) Contrasting the glial response to axon injury in the central and peripheral nervous systems. Dev Cell 28:7-17. CrossRef Medline

Bukrinsky A, Griffin KJ, Zhao Y, Lin S, Banerjee U (2009) Essential role of spi-1-like (spi-1l) in zebrafish myeloid cell differentiation. Blood 113: 2038-2046. CrossRef Medline

Burkel WE (1967) The histological fine structure of perineurium. Anat Rec 158:177-189. CrossRef Medline

Chazotte B (2011) Labeling lysosomes in live cells with LysoTracker. Cold Spring Harbor Protoc 2011:pdb.prot5571. CrossRef Medline

Chen ZL, Yu WM, Strickland S (2007) Peripheral regeneration. Annu Rev Neurosci 30:209-233. CrossRef Medline

Clark JK, O’Keefe A, Mastracci TL, Sussel L, Matise MP, Kucenas S (2014) Mammalian Nkx2.2+ perineurial glia are essential for motor nerve development. Dev Dyn. Advance online publication. Retrieved Jun 30, 2014. doi: 10.1002/dvdy.24158. CrossRef Medline

Dutton KA, Pauliny A, Lopes SS, Elworthy S, Carney TJ, Rauch J, Geisler R, Haffter P, Kelsh RN (2001) Zebrafish colourless encodes sox10 and specifies non-ectomesenchymal neural crest fates. Development 128 : 4113-4125. Medline

Ellett F, Pase L, Hayman JW, Andrianopoulos A, Lieschke GJ (2011) mpeg1 promoter transgenes direct macrophage-lineage expression in zebrafish. Blood 117:e49-e56. CrossRef Medline

Gaudet AD, Popovich PG, Ramer MS (2011) Wallerian degeneration: gain- 
ing perspective on inflammatory events after peripheral nerve injury. J Neuroinflammation 8:110. CrossRef Medline

George EB, Glass JD, Griffin JW (1995) Axotomy-induced axonal degeneration is mediated by calcium influx through ion-specific channels. J Neurosci 15:6445-6452. Medline

Griffin JW, George R, Lobato C, Tyor WR, Yan LC, Glass JD (1992) Macrophage responses and myelin clearance during Wallerian degeneration: relevance to immune-mediated demyelination. J Neuroimmunol 40: 156-166. Medline

Hirata K, Kawabuchi M (2002) Myelin phagocytosis by macrophages and nonmacrophages during Wallerian degeneration. Microsc Res Tech 57: 541-547. CrossRef Medline

Jessen KR, Mirsky R (2008) Negative regulation of myelination: relevance for development, injury, and demyelinating disease. Glia 56:1552-1565. CrossRef Medline

Kelsh RN, Brand M, Jiang YJ, Heisenberg CP, Lin S, Haffter P, Odenthal J, Mullins MC, van Eeden FJ, Furutani-Seiki M, Granato M, Hammerschmidt M, Kane DA, Warga RM, Beuchle D, Vogelsang L, NüssleinVolhard C (1996) Zebrafish pigmentation mutations and the processes of neural crest development. Development 123:369-389. Medline

Kerschensteiner M, Schwab ME, Lichtman JW, Misgeld T (2005) In vivo imaging of axonal degeneration and regeneration in the injured spinal cord. Nat Med 11:572-577. CrossRef Medline

Kimmel CB, Ballard WW, Kimmel SR, Ullmann B, Schilling TF (1995) Stages of embryonic development of the zebrafish. Dev Dyn 203:253-310. CrossRef Medline

Kirby BB, Takada N, Latimer AJ, Shin J, Carney TJ, Kelsh RN, Appel B (2006) In vivo time-lapse imaging shows dynamic oligodendrocyte progenitor behavior during zebrafish development. Nat Neurosci 9:1506-1511. CrossRef Medline

Klimaschewski L, Hausott B, Angelov DN (2013) The pros and cons of growth factors and cytokines in peripheral axon regeneration, Ed 1. New York: Elsevier.

Kristensson K, Olsson Y (1971) The perineurium as a diffusion barrier to protein tracers. Acta Neuropathol 17:127-138. CrossRef Medline

Kucenas S, Takada N, Park HC, Woodruff E, Broadie K, Appel B (2008) CNS-derived glia ensheath peripheral nerves and mediate motor root development. Nat Neurosci 11:143-151. CrossRef Medline

Kucenas S, Wang WD, Knapik EW, Appel B (2009) A selective glial barrier at motor axon exit points prevents oligodendrocyte migration from the spinal cord. J Neurosci 29:15187-15194. CrossRef Medline

Leskovar A, Moriarty LJ, Turek JJ, Schoenlein IA, Borgens RB (2000) The macrophage in acute neuronal injury: changes in cell numbers over time and levels of cytokine production in mammalian central and peripheral nervous systems. J Exp Biol 203:1783-1795. Medline

Lewis GM, Kucenas S (2013) Motor nerve transection and time-lapse imaging of glial cell behaviors in live zebrafish. J Vis Exp 76.

Liu HM, Yang LH, Yang YJ (1995) Schwann cell properties: 3. C-Fos expression, bFGF production, phagocytosis and proliferation during Wallerian degeneration. J Neuropathol Exp Neurol 54:487-496. Medline

Lunn ER, Perry VH, Brown MC, Rosen H, Gordon S (1989) Absence of Wallerian degeneration does not hinder regeneration in peripheral nerve. Eur J Neurosci 1:27-33. CrossRef Medline

MacDonald JM, Beach MG, Porpiglia E, Sheehan AE, Watts RJ, Freeman MR (2006) The Drosophila cell corpse engulfment receptor Draper mediates glial clearance of severed axons. Neuron 50:869-881. CrossRef Medline

Martin SM, O'Brien GS, Portera-Cailliau C, Sagasti A (2010) Wallerian degeneration of zebrafish trigeminal axons in the skin is required for regeneration and developmental pruning. Development 137:3985-3994. CrossRef Medline

McDonald DS, Zochodne DW (2003) An injectable nerve regeneration chamber for studies of unstable soluble growth factors. J Neurosci Methods 122:171-178. CrossRef Medline

McDonald D, Cheng C, Chen Y, Zochodne D (2006) Early events of peripheral nerve regeneration. Neuron Glia Biol 2:139-147. CrossRef Medline

Morris JH, Hudson AR, Weddell G (1972) A study of degeneration and regeneration in the divided rat sciatic nerve based on electron microscopy. Z Zellforsch Mikrosk Anat 124:165-203. CrossRef Medline

Napoli I, Noon LA, Ribeiro S, Kerai AP, Parrinello S, Rosenberg LH, Collins MJ, Harrisingh MC, White IJ, Woodhoo A, Lloyd AC (2012) A central role for the ERK-signaling pathway in controlling Schwann cell plasticity and peripheral nerve regeneration in vivo. Neuron 73:729-742. CrossRef Medline

Nguyen QT, Sanes JR, Lichtman JW (2002) Pre-existing pathways promote precise projection patterns. Nat Neurosci 5:861-867. CrossRef Medline

O’Brien GS, Martin SM, Söllner C, Wright GJ, Becker CG, Portera-Cailliau C, Sagasti A (2009) Developmentally regulated impediments to skin reinnervation by injured peripheral sensory axon terminals. Curr Biol 19: 2086-2090. CrossRef Medline

O’Donnell KC, Vargas ME, Sagasti A (2013) WldS and PGC-1 regulate mitochondrial transport and oxidation state after axonal injury. J Neurosci 33:14778-14790. CrossRef Medline

Parrinello S, Napoli I, Ribeiro S, Wingfield Digby P, Fedorova M, Parkinson DB, Doddrell RD, Nakayama M, Adams RH, Lloyd AC (2010) EphB signaling directs peripheral nerve regeneration through Sox2-dependent Schwann cell sorting. Cell 143:145-155. CrossRef Medline

Peri F, Nüsslein-Volhard C (2008) Live imaging of neuronal degradation by microglia reveals a role for v0-ATPase al in phagosomal fusion in vivo. Cell 133:916-927. CrossRef Medline

Perry VH, Brown MC, Gordon S (1987) The macrophage response to central and peripheral nerve injury. J Exp Med 165:1218-1223. CrossRef Medline

Perry VH, Tsao JW, Fearn S, Brown MC (1995) Radiation-induced reductions in macrophage recruitment have only slight effects on myelin degeneration in sectioned peripheral nerves of mice. Eur J Neurosci 7:271-280. CrossRef Medline

Prendergast A, Linbo TH, Swarts T, Ungos JM, McGraw HF, Krispin S, Weinstein BM, Raible DW (2012) The metalloproteinase inhibitor Reck is essential for zebrafish DRG development. Development 139:1141-1152. CrossRef Medline

Rhodes J, Hagen A, Hsu K, Deng M, Liu TX, Look AT, Kanki JP (2005) Interplay of Pu.1 and Gatal determines myelo-erythroid progenitor cell fate in zebrafish. Dev Cell 8:97-108. CrossRef Medline

Rosenberg AF, Wolman MA, Franzini-Armstrong C, Granato M (2012) In vivo nerve-macrophage interactions following peripheral nerve injury. J Neurosci 32:3898-3909. CrossRef Medline

Röyttä M, Salonen V, Peltonen J (1987) Reversible endoneurial changes after nerve injury. Acta Neuropathol 73:323-329. CrossRef Medline

Scaravilli F (1984) Regeneration of the perineurum across a surgically induced gap in a nerve encased in a plastic tube. J Anat 139:411-424. Medline

Schmidt H, Rickert C, Bossing T, Vef O, Urban J, Technau GM (1997) The embryonic central nervous system lineages of Drosophila melanogaster. Dev Biol 189:186-204. CrossRef Medline

Schroder J, May R, Weis J (1993) Perineurial cells are the first to traverse gaps of peripheral nerves in silicone tubes. Clin Neurol Neurosurg 95 [Suppl]:S78-S83.

Thomas PK, Jones DG (1967) The cellular response to nerve injury: II. Regeneration of the perineurium after nerve section. J Anat 101:45-55. Medline

Vargas ME, Barres BA (2007) Why Is Wallerian degeneration in the CNS so slow? Annu Rev Neurosci 30:153-179. CrossRef Medline

Villegas R, Martin SM, Donnell KC, Carrillo SA, Sagasti A, Allende ML (2012) Dynamics of degeneration and regeneration in developing zebrafish peripheral axons reveals a requirement for extrinsic cell types. Neural Dev 7:19. CrossRef Medline

Waller A (1850) Experiments on the section of the glossopharyngeal and hypoglossal nerves of the frog, and observations of the alterations produced thereby in the structure of their primitive fibres. Philos Trans R Soc Lond B Biol Sci 140:423-429.

Wang JT, Medress ZA, Barres BA (2012) Axon degeneration: molecular mechanisms of a self-destruction pathway. J Cell Biol 196:7-18. CrossRef Medline

Webber C, Zochodne D (2010) The nerve regenerative microenvironment: early behavior and partnership of axons and Schwann cells. Exp Neurol 223:51-59. CrossRef Medline

Witzel C, Rohde C, Brushart TM (2005) Pathway sampling by regenerating peripheral axons. J Comp Neurol 485:183-190. CrossRef Medline

Ziegenfuss JS, Doherty J, Freeman MR (2012) Distinct molecular pathways mediate glial activation and engulfment of axonal debris after axotomy. Nat Neurosci 15:979-987. CrossRef Medline

Zochodne DW (2012) The challenges and beauty of peripheral nerve regrowth. J Peripher Nerv Syst 17:1-18. CrossRef Medline 